\title{
Caveolae, CAVIN1, and lipid peroxidation mediate the oxidative stress response
}

Yeping $\mathrm{Wu}^{1}$, Ye-Wheen $\mathrm{Lim}^{1}$, David A. Stroud ${ }^{2}$, Nick Martel ${ }^{1}$, Thomas E. Hall ${ }^{1}$, Harriet P. Lo ${ }^{1}$, Charles Ferguson ${ }^{1}$, Michael T. Ryan ${ }^{3}$, Kerrie-Ann McMahon ${ }^{1, *}$ and Robert G. Parton ${ }^{1,4, *}$

${ }^{I}$ The University of Queensland, Institute for Molecular Bioscience, 4072, Brisbane, Australia

${ }^{2}$ The University of Melbourne, Department of Biochemistry and Pharmacology and The Bio21

Molecular Science and Biotechnology Institute, 3052, Parkville, Australia

${ }^{3}$ Monash University, Department of Biochemistry and Molecular Biology, Monash Biomedicine

Discovery Institute, 3800, Melbourne, Australia

${ }^{4}$ The University of Queensland, Centre for Microscopy and Microanalysis, 4072, Brisbane, Australia

*Correspondence: k.mcmahon3@uq.edu.au; r.parton@imb.uq.edu.au.

Running title: Caveolae as oxidative stress sensors 


\title{
Caveolae, CAVIN1, and lipid peroxidation mediate the oxidative stress response
}

\begin{abstract}
Caveolae have been linked to a number of biological functions but their precise roles are as yet unclear. Here we have undertaken an unbiased approach to characterize the cellular proteome regulated by the caveolar structural protein, CAVIN1, by utilizing genome-edited cells together with whole cell quantitative proteomics. Pathway analysis identified the cellular response to oxidative stress as the most significant effect of CAVIN1 loss. Functional experiments showed that sensitivity to oxidative stress was compromised in CAVIN1-null cells and zebrafish knockout lines. Mechanistic studies identified oxidative stress-triggered lipid peroxidation as the novel upstream mechanism for caveolar disassembly and release of CAVIN1. Disassembly of caveolae allows direct interaction of CAVIN1 and nuclear factor erythroid 2-related factor 2 (NRF2), a key antioxidant activator. This causes NRF2 sequestration and degradation in the cytosol, inhibiting its transcriptional function in the nucleus. Thus caveolae, via lipid peroxidation and CAVIN1 release, regulate cellular susceptibility to oxidative stress-induced ferroptosis.
\end{abstract}

Keywords: caveolae/CAVIN1/lipid peroxidation/NRF2/oxidative stress/proteomics

\section{Introduction}

Caveolae are small invaginations at the plasma membrane (PM) of nearly all mammalian cells. Caveolar alterations have been extensively linked to human disease conditions. Despite many hypotheses, the mechanism underlying the role of caveolae in different disease conditions is poorly explored. A unifying hypothesis which could link these diverse effects of caveolar dysfunction is currently lacking. Caveolae are generated by integral membrane proteins, caveolins, and cytoplasmic proteins, cavins. In the past, studies on caveolae focused on caveolins and their direct interaction with signalling proteins (Couet, Li et al., 1997) but these models have been questioned (Byrne, Dart et al., 2012, Collins, Davis et al., 2012). In recent years attention has turned to the newly discovered cavins (Bastiani, Liu et al., 2009, Hill, Bastiani et al., 2008b, Parton \& del Pozo, 2013). These abundant structural proteins are increasingly linked to cancer (Lee, Byun et al., 2008, Nassar, Moon et al., 2013) and other 
disease conditions (Hayashi, Matsuda et al., 2009) with different roles from caveolins (Inder, Ruelcke et al., 2014, Moon, Lee et al., 2014). This demonstrates that caveolar function, and dysfunction in disease, cannot be understood without examining the roles of cavins.

Caveolae have been shown to flatten in response to increased membrane tension induced by hypo-osmotic treatment or mechanical stretching (Gambin, Ariotti et al., 2014, Sinha, Koster et al., 2011). This results in a loss of caveolar structure, leading to a decreased association of caveolins and cavins (Cheng, Mendoza-Topaz et al., 2015, Sinha et al., 2011, Yeow, Howard et al., 2017) and the redistribution of cavins into the cytosol (Gambin et al., 2014, McMahon, Wu et al., 2019, Sinha et al., 2011). Emerging evidence has shown that "non-mechanical force" can also lead to cavin release from caveolae. For example, insulin-activated signal can induce the release of CAVIN1 from caveolae resulting in its targeting to the nucleus and regulation of ribosomal RNA synthesis in adipocytes (Liu \& Pilch, 2016). Additionally, upon UV irradiation, CAVIN3 can be redistributed into the cytoplasm and nucleus to promote apoptosis (McMahon et al., 2019). Thus, we proposed that diverse cellular conditions and stimuli can release cavins from the cell membrane and lead to changes in intracellular targets (Parton, McMahon et al., 2020b). However, little is known about the downstream signaling pathways of cavins and the functional relevance of the cavin release-signaling model.

Here, we investigated caveolar signaling by combining gene editing technology with unbiased whole cell quantitative proteomics (Stroud, Surgenor et al., 2016) and by the use of zebrafish knockout models. We show that oxidative stress responsive pathways, regulated by the antioxidant activator, NRF2, are dramatically affected by loss of CAVIN1. Oxidative stress leads to CAVIN1 release from caveolae by induction of plasma membrane lipid peroxidation. The released intracellular CAVIN1 associates with NRF2 to cause its degradation and positively regulate ferroptosis in response to severe oxidative damage. Therefore, loss of caveolae can increase resistance to oxidative stress and promote cancer cell survival.

\section{Results}

\section{Cellular stress responses are impacted by loss of CAVIN1.}

We chose HeLa cells as a well-characterized model system that has been used extensively for caveola studies (Hirama, Das et al., 2017, Sinha et al., 2011). Wild-type (WT) HeLa cells 
express CAV1, CAVIN1 and CAVIN3 but not CAVIN2 (Fig. EV1A). HeLa cell lines lacking CAVIN1 were generated by genome editing (Fig. EV1B-G) and further characterized by electron microscopy (EM) (Fig. EV1T), light microscopy (Fig. EV1M-S) and for protein and mRNA levels (Fig. EV1H-L).

Mass spectrometry (MS)-based quantitative proteomic analysis (Stroud et al., 2016) was performed to profile changes in protein abundance in the parental and CAVINI KO lines. High confidence protein expression differences between WT and CAVIN1 KO HeLa cells were determined for 3512 cellular proteins using label-free MS analysis (Fig.1A; Table EV1). Statistical analysis revealed that 291 proteins were significantly downregulated, and 571 proteins were significantly upregulated in CAVIN1 KO cells (Fig.1B and C; Table EV1). The significantly changed proteins were subjected to gene ontology analysis and causal network analysis using Ingenuity Pathway Analysis (IPA). The top impacted pathways (see entire list in Table EV2) are described in detail in the Appendix Text.

Cellular responses to stress were significantly affected by CAVIN1 loss (Table EV2). This is associated with a number of upregulated antioxidant enzymes, thioredoxin proteins, heat shock proteins, serpin proteins and proteins involved in NAPDH oxidase mediated redox signaling (see entire list in Table EV2). Particularly, NRF2-mediated oxidative stress response was identified as the most upregulated toxicity pathway in CAVIN1 KO cells (Fig. 1D). Upstream regulator analysis (URA) further revealed NRF2 (also known as NFE2L2) as a significant upstream regulator in CAVINI KO cells (Fig. 1E; entire URA list presented in Table EV2).

NRF2 is the key transcriptional regulator of oxidative stress response that activates the gene expression of antioxidant enzymes and mediates antioxidant response. Under steady state conditions, NRF2 is rapidly degraded in the cytosol via the ubiquitin-proteasomal pathway (Velichkova \& Hasson, 2005). Upon oxidative stress, NRF2 translocates into the nucleus, allowing newly synthesized NRF2 to avoid degradation and to activate downstream gene expression (Kansanen, Kuosmanen et al., 2013). Although NRF2 was not detected in HeLa cells by MS, possibly due to its rapid turnover and low abundance at resting state conditions (Velichkova \& Hasson, 2005), the upregulation of NRF2 in CAVIN1 KO cells was verified by western blot analysis, in whole cell lysates (Fig. 3A and B). Forty-one significantly upregulated proteins were identified as NRF2 downstream targets in CAVIN1 KO cells (Table 1). The interaction networks of these proteins were clustered into different biological 
processes. As shown in Fig. 1F, a number of NRF2 downstream targets function in the oxidation-reduction process (12 of 41; nodes labeled as green). Several antioxidant enzymes such as thioredoxin reductase (TXNRD) 1, TXNRD2, triosephosphate isomerase 1 (TPI) (2.1-fold) and thioredoxin (TXN) (1.4-fold) were highly upregulated (Table 1). In addition, TALDO1, fructose-bisphosphate A (ALDOA) and NADPH-dependent quinone dehydrogenase 1 (NQO1) involved in the regeneration of NAPDH (Perl, Qian et al., 2006, $\mathrm{Wu}$, Cui et al., 2011) that contributes to the antioxidant response, were significantly upregulated 2.2-fold, 1.9-fold (Table 1) and 0.7-fold (Table EV1) respectively.

Hydrogen peroxide $\left(\mathrm{H}_{2} \mathrm{O}_{2}\right)$-induced adaptation to oxidative stress is strongly dependent on the NRF2-induced upregulation of $20 \mathrm{~S}$ proteasomes. This important adaptive response is highly conserved through evolution (Pickering, Staab et al., 2013) due to its essential role in the proteolytic removal of oxidatively damaged proteins, enabling cells to cope with oxidative stress to maintain normal cellular function and to allow cell survival (Pickering, Koop et al., 2010). A number of components that constitute the $20 \mathrm{~S}$ proteasome catalytic core (Fig. 1F, protein nodes labeled as cyan) including proteasome subunit alpha type (PSMA) proteins PSMA-4 (2.0-fold), -6 (2.0-fold) and -7 (1.6-fold), as well as proteasome subunit beta type (PSMB) proteins PSMB-1 (2.1-fold) and -5 (2.9-fold), were significantly upregulated (Table 1), suggesting CAVIN1 depletion mediates an adaptive response to oxidative stress.

\section{CAVIN1 ablation increases cellular antioxidant capacity.}

The above data strongly suggest that CAVIN1 plays a specific role, either directly or indirectly, in the cellular response to oxidative stress. In view of the prominent changes observed in the NRF2-mediated oxidative stress responsive pathway of CAVIN1 KO cells, we sought to assess NRF2-regulated antioxidant capacity in cells and zebrafish lacking CAVIN1 to elucidate the molecular mechanism(s) underlying the potential regulation of CAVIN1 on the oxidative stress responsive pathway.

First, the levels of intracellular reactive oxygen species (ROS) were measured. In addition to HeLa cells, we studied the epidermoid carcinoma cell line, A431, as an independent cell line.

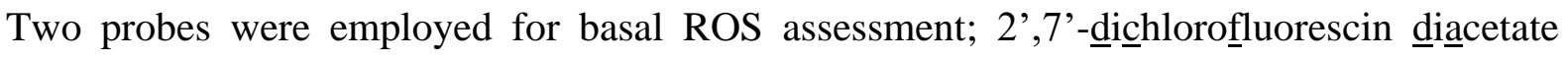
$\left(\mathrm{H}_{2} \mathrm{DCFDA}\right)$ and CellROXGreen. Detection of DCF fluorescence confirmed a significant decrease in basal intracellular ROS in CAVIN1 KO cells (Fig. 2A). CAVIN1-FLAG re- 
expression restored ROS content to WT levels in CAVIN1 KO cells (Fig. 2A). In agreement with this, knockdown of CAVIN1 in A431 cells also led to reduced ROS levels (Fig. EV3A). Use of CellROX Green also showed a significant downregulation of ROS in CAVIN1 KO cells (Fig. 2B and C). Although CAV1 was downregulated in CAVIN1 KO cells (Fig. EV1KL), re-expression of HA-CAV1 showed no effect on basal ROS levels (Fig. EV3B). This suggests that reduction of ROS under steady state conditions is exclusively caused by CAVIN1 loss.

Next, to investigate whether the differentially regulated ROS in CAVIN1 KO cells is due to an alteration in antioxidant capacity, a peroxide scavenging assay (Mukhopadhyay, Dasgupta et al., 2015) (Fig. 2D) was performed with Vitamin C, a well-characterized antioxidant (Mukhopadhyay et al., 2015), as a positive control. CAVIN1 KO cell lysates showed a significantly enhanced antioxidant capacity (Fig. 2E and F) indicating that loss of CAVIN1 causes upregulation of buffering proteins.

Endogenous basal ROS activate specific enzymes and induce signaling pathways to maintain proper cellular function including cell proliferation (Milkovic, Cipak Gasparovic et al., 2019). We observed a significant reduction in proliferation of CAVIN1 KO cells after growth for 48 $\mathrm{h}$ and $72 \mathrm{~h}$ (Fig. 2G). To verify if the decrease in cell growth rate observed in CAVIN1 KO cells resulted from the reduction of basal ROS, WT cells were treated with serial dilutions of Vitamin $\mathrm{C}$ where the highest concentration $(0.2 \mathrm{mg} / \mathrm{mL})$ efficiently neutralized ROS (Fig. 2H). PrestoBlue assays showed that Vitamin C suppressed cell growth of WT cells in a dosedependent manner (Fig. 2I). Moreover, Vitamin C at or above $0.05 \mathrm{mg} / \mathrm{mL}$ abolished the difference in the cell growth abilities of WT and CAVIN1 KO cells (Fig. 2I), suggesting a correlation between decreased cell growth and reduced basal ROS levels in CAVIN1 KO cells.

\section{CAVIN1 KO cells and zebrafish are oxidative stress-resistant.}

As enhanced antioxidant capacity was observed in CAVIN1 KO cells, we next examined the cellular response to oxidative stress. $\mathrm{H}_{2} \mathrm{O}_{2}$ was applied at a non-cytotoxic concentration $(0.2$ $\mathrm{mM}$ ) (Fig. 2O) for $30 \mathrm{~min}$ and ROS levels monitored for the following $12 \mathrm{~h}$ (Fig. 2J). ROS levels returned to steady state levels in the CAVIN1 KO cell cultures within $4 \mathrm{~h}$ whereas levels in WT cells only returned to control levels after $12 \mathrm{~h}$ (Fig. 2J). Similar results were obtained with CellROX Green; ROS levels were restored to basal levels after 4 h in CAVIN1 KO cells, whereas WT cells at this timepoint showed no significant reduction in ROS levels 
(Fig. 2K and L). These data show that CAVIN1 KO cells have upregulated antioxidant activity.

Next, we examined whether increased antioxidant capacity observed in CAVIN1 KO HeLa cells is an evolutionarily-conserved feature of tissues lacking CAVIN1. For this, we used the zebrafish as a vertebrate model system. The zebrafish expresses two CAVIN1 paralogs, Cavin1a and Cavin1b (Hill, Bastiani et al., 2008a, Lo, Nixon et al., 2015). To generate a complete Cavin1 double knockout (DKO) zebrafish line, hereby referred to as the cavinla/lb DKO line, we generated a cavinla KO line (cavinla ${ }^{-/-u q 10 r p}$ ) using CRISPR/Cas9 technology and crossed this line to our previously characterized cavin $1 b$ KO line (cavin1b $\left.{ }^{-/ u q 7 r p}\right)(\mathrm{Lim}$, Lo et al., 2017); offspring were bred to homozygosity and characterized (Fig. EV2). Cavinla/lb DKO zebrafish lacked caveolae in all tissues examined (Fig. EV2G). Despite a significant downregulation of both cavinl paralogs indicating nonsense-mediated decay (Conti \& Izaurralde, 2005), the cavinla/1b DKO line was both fertile and viable, with no observable defects in early survivorship, gross morphology or adipose development (Fig. EV2A-D), similar to our single cavin1b mutants (Lim et al., 2017). Also similar to the single cavin $1 b$ mutants, cavin la/lb DKO embryos possess defects in body length and notochord lesions (Fig. EV2E and F). We then investigated the ROS scavenging activity of cavinla/lb DKO zebrafish. Live zebrafish embryos (2 days post-fertilization [dpf]) were incubated in 2 $\mathrm{mM} \mathrm{H}_{2} \mathrm{O}_{2}$ for $1 \mathrm{~h}$ and stained with $\mathrm{H}_{2}$ DCFDA $(20 \mu \mathrm{M})$ for $30 \mathrm{~min}$ to detect ROS. The myotome occupies a large proportion of the zebrafish trunk region, therefore we focused on the DCF signal in the skeletal muscle cells (Fig. 2M). While $\mathrm{H}_{2} \mathrm{O}_{2}$-treated WT zebrafish showed significantly increased ROS levels, $\mathrm{H}_{2} \mathrm{O}_{2}$-treated cavinla/lb DKO zebrafish showed similar ROS levels to untreated cavinla/lb DKO zebrafish (Fig. $2 \mathrm{M}$ and $\mathrm{N}$ ). These in vivo results suggest that increased antioxidant capacity is a conserved feature of cells lacking CAVIN1.

Enhanced antioxidant capacity has been shown to facilitate cancer cell survival by eliminating ROS to limit oxidative damage caused by ROS at toxic levels (Recktenwald, Kellner et al., 2008). Therefore, we compared the tolerance of WT and CAVIN1 KO cells to severe oxidative stress. A cell survival curve showed that a high dose $(0.6$ and $0.8 \mathrm{mM})$ treatment for $24 \mathrm{~h}$ was able to induce cytotoxicity in both WT and CAVIN1 KO cells, but CAVIN1 KO cells showed a significantly increased survival rate (Fig. 2O). Moreover, we observed reduced levels of the DNA damage marker $\gamma \mathrm{H} 2 \mathrm{AX}$, as well as apoptotic marker cleaved caspase 3, in CAVIN1 KO cells following high-dose $\mathrm{H}_{2} \mathrm{O}_{2}$ treatment (Fig. 2P). 
Collectively, these results suggest that CAVIN1 loss causes enhanced antioxidant capacity that leads to cellular resistance to cell death induced by severe oxidative stress.

\section{CAVIN1 regulates $N R F 2$ nuclear import and function.}

In view of the increased antioxidant capacity of cells and animals lacking CAVIN1, as well as the identification of NRF2 as a key upstream regulator (Fig. 1F), we investigated the interplay between CAVIN1 and NRF2. To assess the effect of CAVIN1 on the responsive properties of NRF2 to oxidative stress, protein stability, nuclear translocation and transcription activity of NRF2 was compared between WT and CAVIN1 KO HeLa cells.

First, we detected increased protein levels of NRF2 in CAVIN1 KO cells under steady state conditions (Fig. 3A and B). Next, NRF2 expression was monitored following $\mathrm{H}_{2} \mathrm{O}_{2}$ treatment over a time-course from 20 to $120 \mathrm{~min}$. Western blot and densitometry analysis revealed a significant upregulation in NRF2 protein levels in CAVIN1 KO cells after exposure to $\mathrm{H}_{2} \mathrm{O}_{2}$ for $40 \mathrm{~min}$, whereas NRF2 showed no significant change in WT cells (Fig. 3A and B). Immunofluorescence confirmed a significant increase in the nuclear levels of NRF2 in CAVIN1 KO cells under both steady state and oxidative stress conditions (Fig. 3C and D). Re-expression of CAVIN1-GFP caused NRF2 sequestration in the cytoplasm in both untreated and $\mathrm{H}_{2} \mathrm{O}_{2}$-treated CAVIN1 KO cells (Fig. 3F), which was not observed in cells expressing GFP alone (Fig. 3E). In the cavin/caveola-deficient MCF-7 cell line (McMahon et al., 2019), NRF2 exhibited a predominant nuclear distribution (Fig. EV3C), similar to observations in CAVIN1 KO HeLa cells. In these cells, CAVIN1-GFP re-expression was able to induce redistribution of NRF2 to the cytoplasm (Fig. EV3C). These data together suggest that CAVIN1 is responsible for NRF2 sequestration in the cytosol.

Next, we assessed whether increased NRF2 nuclear import affects the transcriptional levels of NRF2 downstream targets in CAVIN1 KO cells. The antioxidant enzyme and prominent NRF2 target, NQO1 (Dhakshinamoorthy \& Jaiswal, 2001), was upregulated in our proteomic analysis (Table EV1); real-time PCR demonstrated significantly increased NQO1 expression levels in CAVIN1 KO cells and cavinla/lb DKO zebrafish in response to $\mathrm{H}_{2} \mathrm{O}_{2}$ treatment (Fig. 3G and $\mathrm{H}$ ). These results confirmed increased transcriptional activity of NRF2 in cells and tissues lacking CAVIN1. 


\section{CAVIN1 mediates NRF2 ubiquitination and degradation.}

Cytoplasmic NRF2 is rapidly degraded via the ubiquitin-proteasome pathway (Kansanen et al., 2013). We validated the role of CAVIN1 in sequestrating NRF2 in the cytoplasm upon oxidative stress and next asked whether CAVIN1 affects ubiquitin-mediated degradation of NRF2. First, cells were treated with MG132 for proteasome inhibition prior to the assessment of NRF2 ubiquitination levels. Proximity ligation assay (PLA) was performed to visualize the in situ NRF2-ubiquitin association in cells, where the red puncta indicate positive association. Quantification of PLA signal confirmed that CAVIN1 ablation led to significant loss of NRF2-ubiquitin association under steady state conditions (Fig. 3I-K). $\mathrm{H}_{2} \mathrm{O}_{2}$ treatment significantly increased NRF2-ubiquitin association in a dose-dependent manner in WT cells (Fig. 3I and K) but showed no effect in CAVIN1 KO cells (Fig. 3J and K). Consistently, coimmunoprecipitation revealed that no ubiquitinated NRF2 was detected in CAVIN1 KO cells with or without $\mathrm{H}_{2} \mathrm{O}_{2}$ treatment (Fig. 3L). These results together suggest that CAVIN1 expression is essential for NRF2 ubiquitination.

To evaluate NRF2 protein stability, changes in NRF2 expression levels were examined in WT and CAVIN1 KO cells over a $24 \mathrm{~h}$ period of cycloheximide (CHX) treatment (Fig. 3M and $\mathrm{N}$ ). Western blots revealed a decrease in NRF2 protein levels after a $12 \mathrm{~h}$ chase in WT cells. In contrast, no obvious downregulation of NRF2 protein was observed after $24 \mathrm{~h}$ in CAVIN1 KO cells. CAVIN1-GFP re-expression strongly promoted the degradation of NRF2 protein in CAVIN1 KO cells, where a decreased NRF2 protein level was observed after a $6 \mathrm{~h}$ CHX chase. This experiment verified that CAVIN1 is directly linked to protein stability of NRF2.

\section{Oxidative stress leads to CAVIN1 release from caveolae.}

CAVIN1 as a caveolar coat protein is mainly localized on the cell surface. NRF2 is predominantly in the cytoplasm under steady state conditions (although a surface pool was also detectable) (Fig. 3C). The difference in subcellular localization for these two proteins raise the question of how CAVIN1 regulates NRF2 activity in WT cells. As cavins can be released from caveolae into the cytosol and nucleus under specific stress conditions (Gambin et al., 2014, Hill et al., 2008b, Liu \& Pilch, 2008, Liu \& Pilch, 2016, McMahon et al., 2019, Sinha et al., 2011) we examined whether oxidative stress would also induce CAVIN1 release. CAVIN1 was localized at the cell surface in untreated cells (Fig. 4A) but following $\mathrm{H}_{2} \mathrm{O}_{2}$ 
treatment, CAVIN1 exhibited a diffuse localization in the cytosol (Fig. 4B and C). Live cell imaging also showed reduced colocalization between CAVIN1 and CAV1 and redistribution of CAVIN1 into the cytosol in the $\mathrm{H}_{2} \mathrm{O}_{2}$-treated cell (Fig. 4D-I), suggesting dissociation of CAVIN1 from caveolae. A diffuse pattern of CAV1, which is similar to a non-caveolar CAV1 distribution at the PM (Bastiani et al., 2009), was observed after exposure to $\mathrm{H}_{2} \mathrm{O}_{2}$ for 20 min (Fig. 4H), suggesting partial caveola disassembly.

PLA was then used to detect CAVIN1-NRF2 association. Under steady state conditions, a low signal for CAVIN1 and NRF2 was detected mainly at the PM (Fig. 4J). CAVIN1-NRF2 association was significantly upregulated in a dose-dependent manner in $\mathrm{H}_{2} \mathrm{O}_{2}$-treated WT cells and occurred primarily in the cytosol (Fig. 4J and K). Consistently, the amount of coimmunoprecipitated CAVIN1 with NRF2 (Fig. 4L; quantified in Fig. 4O), as well as coimmunoprecipitated NRF2 with CAVIN1 (Fig. 4M; quantified in Fig. 4P), was increased in cells exposed to $\mathrm{H}_{2} \mathrm{O}_{2}$. Consistent with these observations, redistribution of CAVIN1 to the cytosol in A431 cells was observed by immunofluorescence upon $\mathrm{H}_{2} \mathrm{O}_{2}$ treatment (Fig. EV3E). This was associated with a decreased density of surface caveolae detected by EM (Fig. EV3F-H). An increased CAVIN1-NRF2 association was also observed in $\mathrm{H}_{2} \mathrm{O}_{2}$-treated A431 cells (Fig. EV3I). Collectively, these data suggest that redistribution of CAVIN1 from caveolae is a general effect in different cell lines upon oxidative stress, allowing CAVIN1 to functionally associate with NRF2 in the cytosol.

\section{Lipid peroxidation is responsible for CAVIN1 release.}

Caveolar formation depends on the interactions between caveolins, cavins and lipids (Hayer, Stoeber et al., 2010, Kovtun, Tillu et al., 2014, Parton, Hanzal-Bayer et al., 2006). It has been previously suggested that CAVIN1 is associated with the PM through electrostatic interactions with phosphoinositide (PI) lipids (Kovtun et al., 2014) and phosphatidylserine (Tillu, Lim et al., 2018) and we have proposed that specific lipid species may be enriched in caveolae (Parton, Kozlov et al., 2020a). Lipid peroxidation is considered to be one of the main mechanisms underlying oxidative stress-induced damage to the PM (Wong-Ekkabut, $\mathrm{Xu}$ et al., 2007). We hypothesized that lipid peroxidation may be a potential mechanism for caveola disassembly and CAVIN1 redistribution under oxidative stress. To test this idea, we used a lipid peroxidation sensor BODIPY-C11 (B-C11) that incorporates into cellular membranes in live cells and exhibits a shift of peak fluorescence emission from $590 \mathrm{~nm}$ (reduced signal) to $510 \mathrm{~nm}$ (oxidized signal) upon hydroperoxidation. Downregulation of the 
reduced B-C11 (re-B-C11) signal was observed along with the upregulation of the oxidized B-C11 (ox-B-C11) signal in $\mathrm{H}_{2} \mathrm{O}_{2}$-treated cells compared to untreated cells (Fig. 4Q). A significant increase in the quantified ox-B-C11:re-B-C11 ratio in $\mathrm{H}_{2} \mathrm{O}_{2}$-treated cells indicated lipid peroxidation upon $\mathrm{H}_{2} \mathrm{O}_{2}$ treatment (Fig. 4R). The pre-treatment of a lipid soluble antioxidant $\alpha$-Tocopherol, previously shown to be protective against lipid peroxidation (Ni \& Eng, 2012), restored re-B-C11 signal to steady state levels in $\mathrm{H}_{2} \mathrm{O}_{2}$-treated cells (Fig. 4Q and R). Similar results were obtained in A431 cells (Fig. EV3K and L). Treatment with cumene hydroperoxide, a well-characterized lipid peroxidation agent (Weiss \& Estabrook, 1986) was included as a positive control (Fig. EV3M and N).

Having optimized methods to detect lipid peroxidation, we next asked whether lipid peroxidation is involved in CAVIN1 release upon oxidative stress. Immunofluorescence revealed CAVIN1 redistribution and sequestration of NRF2 in the cytosol following $\mathrm{H}_{2} \mathrm{O}_{2}$ treatment (Fig. 4S). In the presence of $\alpha$-Tocopherol, CAVIN1 remained surface-localized in $\mathrm{H}_{2} \mathrm{O}_{2}$-treated cells, and NRF2 was able to translocate to the nucleus (Fig. 4S, red arrows). $\alpha$ Tocopherol treatment also abrogated the $\mathrm{H}_{2} \mathrm{O}_{2}$-induced increase in CAVIN1-NRF2 association and restored the interaction signal at the PM (Fig. 4T; quantified in Fig. 4U). As an independent test of the role of lipid peroxidation, cells were treated with cumene hydroperoxide. CAVIN1 release was stimulated by cumene hydroperoxide and blocked by $\alpha$ Tocopherol (Fig. EV3O).

We further characterized the role of membrane lipid peroxidation in CAVIN1 release by using a photochemical method and confocal microscopy to bypass enzymatic redox reactions, both with whole cells (Fig. EV4I-M) as well as in discrete cellular regions to specifically initiate lipid peroxidation at the PM (Zou, Graham et al., 2020). Live-cell imaging revealed that $405 \mathrm{~nm}$ high-power laser pulses applied on the PM led to increased ox-B-C11 signal (Video EV1; quantified in Fig. EV4A) compared to the untreated cells (Video EV2; quantified in Fig. EV4B). This treatment caused a reduction in CAVIN1-GFP puncta at the PM over time in the laser-treated cell (Video EV3; Fig. EV4C-E) in comparison to untreated cells (Video EV4; Fig. EV4F-H). This was also demonstrated by laser-treating regions of the monolayer containing multiple cells. Cells in the laser-treated region exhibited increased oxC-B11 signal (Fig. 5A-D) and less CAVIN1 puncta at the PM compared to the cells in the untreated region (Fig. 5I). Pre-treatment with $\alpha$-Tocopherol inhibited the lipid peroxidation (Fig. 5G and $\mathrm{H}$ ) and rescued the loss of CAVIN1 puncta at the PM (Fig. 5E, F and I). These 
results implicate lipid peroxidation in triggering partial disassembly of caveolae and release of CAVIN1 into the cytoplasm.

\section{CAVIN1 KO cells are resistant to ferroptosis.}

Peroxidation of unsaturated fatty acid chains in membrane lipids can be induced under oxidative stress triggering ferroptosis (Ubellacker, Tasdogan et al., 2020). NRF2 has been shown to be a negative regulator of lipid peroxidation and ferroptosis since many NRF2 downstream targets are anti-ferroptosis genes (Dodson, Castro-Portuguez et al., 2019). In view of the upregulated NRF2 activity in CAVIN1 KO cells, we therefore compared the sensitivity of WT and CAVIN1 KO cells to ferroptosis. To induce ferroptosis, cells were treated with a glutathione peroxidase (GPX4) inhibitor RSL3 (Sui, Zhang et al., 2018) and a cystine-glutamate transporter inhibitor Erastin2 (Riegman, Sagie et al., 2020). Cell impermeable SYTOX Green nuclear acid dye was used to indicate ferroptosis (Riegman et al., 2020). $76.2 \%$ and $44.0 \%$ of WT cells were stained with SYTOX Green after 24-h RSL3 and Erastin2 treatment, respectively, whereas no cells were SYTOX Green positive in the untreated WT cells (Fig. 5J and L). This shows induction of ferroptosis by RSL3 and Erastin2, which can be effectively inhibited by pre-treatment with $\alpha$-Tocopherol (Fig. 5J and L). In contrast, only $7.8 \%$ of CAVIN1 KO cells were stained with SYTOX Green after RSL3 treatment (Fig. 5K and M) and no significant difference was observed between Erastin2treated $(4.7 \%)$ and untreated $(0.0 \%)$ CAVIN1 KO cells (Fig. 5K and M). We further assessed the protein levels of the key reductase GPX4 during ferroptosis as an indicator of the level of ferroptosis (Li, Cao et al., 2020). Western blot revealed a significant upregulation of basal GPX4 protein levels in CAVIN1 KO cells (Fig. 5N and O). Upon RLS3 treatment, a significant downregulation of GPX4 protein levels (-56\%) was observed in RSL3-treated WT cells, which was rescued by pre-treatment with $\alpha$-Tocopherol. In contrast, only a $26 \%$ reduction of GPX4 protein levels was observed in RSL3-treated CAVIN1 KO cells, not significantly different from untreated CAVIN1 KO cells (Fig. 5N and O). Similarly, Erastin2 treatment caused less reduction of GPX4 protein in CAVIN1 KO cells (-16\%) compared to WT cells (-31\%) (Fig. 5N and O). In both cases, reduction of GPX4 levels could be rescued by pre-treatment with $\alpha$-Tocopherol. These results show resistance of CAVIN1 KO cells to lipid peroxidation-triggered ferroptosis. 
Together, our study shows that lipid peroxidation under oxidative stress is responsible for CAVIN1 release from caveolae providing a mechanism by which CAVIN1 can interact with NRF2 to sequester it in the cytosol and promote its degradation. This subsequently leads to cell death upon severe oxidant attack (schematic conclusion in Fig. 6).

\section{Discussion}

Our results have implications for understanding both the effect of caveola loss in cancer cells and the physiological role of caveolae as part of the cellular response to stress. First, we show that the loss of caveolae, which occurs in cancer cells with abnormal expression of CAV1 or/and CAVIN1 (Hill et al., 2008b, McMahon et al., 2019, Moon et al., 2014), would cause the upregulation of NRF2-mediated antioxidant pathway due to the impaired ubiquitination of NRF2 and consequently lead to reduced ROS levels. This can potentially insensitize cells to ferroptotic cell death, for example during cancer cell metastasis, increasing survival of migrating cancer cells (Ubellacker et al., 2020).

Second, we propose a scenario in which caveolae can regulate the cellular response to extreme oxidative stress. Oxidative stress-induced lipid peroxidation results in cellular membrane damage (Wong-Ekkabut et al., 2007). We propose that caveolae, due to their unique lipid composition (Parton et al., 2020a) are particularly sensitive to lipid peroxidation. This causes CAVIN1 dissociation from caveolae and its interaction with NRF2 in the cytoplasm, which is essential for the ubiquitination and degradation of NRF2. This negative regulation of NRF2 mediated by released CAVIN1 upon lipid peroxidation leads to ferroptosis. In cells without caveolae, we observed more rapid NRF2 accumulation in the nucleus upon oxidative stress and reduced cellular sensitivity to lipid peroxidation-induced ferroptosis. While our studies strongly suggest that under these conditions the primary effect of oxidative stress is to cause cavin release by modulating caveolar disassembly, higher concentrations of $\mathrm{H}_{2} \mathrm{O}_{2}$ can also trigger caveolin redistribution to early endosomes (Jung, Sierecki et al., 2018). Whether or how these different effects of oxidative stress on caveolae are linked awaits further analysis.

Interestingly, depending on the levels present, ROS affect cellular processes differently. Under steady state conditions, certain levels of ROS content are required for physiological cellular functions such as cell proliferation (Milkovic et al., 2019). In our study, CAVIN1 KO cells with reduced basal ROS levels exhibit suppressed cell growth ability (Fig. 2G), 
indicating that the role of caveolae in maintaining basal ROS levels ensures normal cellular function. However, under oxidative stress, which can be induced during pathological conditions (El-Kenawi \& Ruffell, 2017), ROS can be elevated and lead to harmful cellular effects such as DNA damage that may initiate or promote cancer (El-Kenawi \& Ruffell, 2017). We show that, upon severe oxidant damage, caveolae maintain cellular sensitivity to ferroptosis through the negative regulation of the NRF2-mediated antioxidant pathway. Conversely, loss of caveolae activates NRF2 downstream antioxidant enzymes that confers cells with enhanced coping abilities to allow increased survival from ferroptosis. These findings have revealed that caveolae can act as sensors to oxidative stress and in doing so, mediate the elimination of severely damaged cells by restraining antioxidant-mediated detoxification. This process drives oxidant-damaged cancer cells with transforming potential to undergo cell deaths, thereby protecting against oxidative stress-promoted tumorigenesis and cancer progression. Loss of caveolae, as exhibited by cells in some cancers, would assist with evasion of ferroptosis under oxidative stress and contribute to genomic instability and cancer development.

The identification of CAVIN1 as a negative regulator of the NRF2-related antioxidant defensive pathway, reveals a novel functional significance for caveolae in the regulation of oxidative stress that can occur within the tumour environment. A number of studies have shown that the up-regulation and activation of NRF2 is responsible for drug or radiation resistance in many cancers and is directly linked to poor prognosis (Syu, Chi et al., 2016, Wang, Zhang et al., 2018), which has been linked to its anti-ferroptosis effect (Dodson et al., 2019, Roh, Kim et al., 2017, Shin, Kim et al., 2018). The inhibition of NRF2 or its downstream antioxidant enzymes is effective in sensitizing tumor cells to chemotherapy of which their cytotoxicity is mediated by ROS (Roh et al., 2017, Shin et al., 2018). Prospectively, CAVIN1/caveola expression level may serve as a potential indicator of chemosensitivity that directs better selection of responsive patients to ROS-inducing cancer therapies. 


\section{Materials and Methods}

\section{Reagents and Tools Table}

\begin{tabular}{|c|c|c|}
\hline Reagent/resource & Reference or source & Identifier or catalog number \\
\hline \multicolumn{3}{|l|}{ Antibodies } \\
\hline Rabbit polyclonal anti-CAVIN1 & ProteinTech & $\begin{array}{l}\text { Cat\# 18892-1-AP, RRID: } \\
\text { AB_10596795 }\end{array}$ \\
\hline Rabbit polyclonal anti-CAVIN1 & Abcam & $\begin{array}{l}\text { Cat\# ab48824, RRID: } \\
\text { AB_882224 }\end{array}$ \\
\hline Rabbit polyclonal anti-CAVIN3 & ProteinTech & $\begin{array}{l}\text { Cat\# 16250-1-AP, RRID: } \\
\text { AB } 2171894\end{array}$ \\
\hline Rabbit polyclonal anti- $\gamma \mathrm{H} 2 \mathrm{AX}$ (S139) & Abcam & $\begin{array}{l}\text { Cat\# ab2893, RRID: } \\
\text { AB_303388 }\end{array}$ \\
\hline Rabbit polyclonal anti-CAVEOLIN1 & $\begin{array}{l}\text { Becton Dickinson } \\
\text { Biosciences }\end{array}$ & $\begin{array}{l}\text { Cat\# 610059, RRID: } \\
\text { AB_397471 }\end{array}$ \\
\hline Rabbit polyclonal anti-Cleaved caspase 3 & $\begin{array}{l}\text { Cell Signaling } \\
\text { Technology }\end{array}$ & $\begin{array}{l}\text { Cat\# 9664, RRID: } \\
\text { AB_2070042 }\end{array}$ \\
\hline Rabbit polyclonal anti-NRF2 & Abcam & $\begin{array}{l}\text { Cat\# ab137550, RRID: } \\
\text { AB_2687540 }\end{array}$ \\
\hline Mouse monoclonal anti-NRF2 & Abcam & $\begin{array}{l}\text { Cat\# ab89443, RRID: } \\
\text { AB_2041334 }\end{array}$ \\
\hline Rabbit polyclonal anti-EHD2 & Abcam & Cat\# ab222888 \\
\hline Rabbit polyclonal anti-PACSIN2 & Sigma Aldrich & $\begin{array}{l}\text { Cat\# SAB1300127, RRID: } \\
\text { AB_10606481 }\end{array}$ \\
\hline Rabbit polyclonal anti-GPX4 & Abcam & $\begin{array}{l}\text { Cat\# ab41787, RRID: } \\
\text { AB_941790 }\end{array}$ \\
\hline Mouse monoclonal anti-ACTB & Merck Millipore & $\begin{array}{l}\text { Cat\# MAB1501, RRID: } \\
\text { AB_2223041 }\end{array}$ \\
\hline Mouse monoclonal anti-Ubiquitin & Sapphire Bioscience & $\begin{array}{l}\text { Cat\# BML-PW8810-0500, } \\
\text { RRID: AB_2051891 }\end{array}$ \\
\hline \multicolumn{3}{|c|}{ Chemicals, Peptides, and Recombinant Proteins } \\
\hline$\overline{\text { RSL3 }}$ & Sigma Aldrich & Cat\# SML2234-5MG \\
\hline Erastin2 & Cayman & Cat\# 27087 \\
\hline$\alpha$-Tocopherol & Sigma Aldrich & Cat\# 258024-5G \\
\hline Vitamin $\mathrm{C}$ & Sigma Aldrich & Cat\# A4544-25G \\
\hline Hydrogen peroxide $(30 \%)$ & Sigma Aldrich & Cat\# H1009-100ML \\
\hline \multicolumn{3}{|l|}{ Critical Commercial Assays } \\
\hline T7 endonuclease I Kit & New England BioLabs & Cat\# E3321 \\
\hline QIAquick PCR Purification Kit & QIAGEN & Cat\# 28104 \\
\hline RNeasy Mini Kit & QIAGEN & Cat\# 74104 \\
\hline CAVIN1 TaqMan Gene Expression assays & $\begin{array}{l}\text { ThermoFisher } \\
\text { Scientific }\end{array}$ & Cat\# 4331182 \\
\hline $\begin{array}{l}\text { Duolink In Situ Detection reagents FAR } \\
\text { RED }\end{array}$ & Sigma Aldrich & Cat\# DUO92013-100RXN \\
\hline PrestoBlue Cell Viability Reagent & Life Technologies & Cat\# A13261 \\
\hline $\begin{array}{l}\text { Image-i }{ }^{\mathrm{TM}} \text { Lipid Peroxidation Kit for live } \\
\text { cell analysis }\end{array}$ & $\begin{array}{l}\text { ThermoFisher } \\
\text { Scientific }\end{array}$ & Cat\# 486148 \\
\hline
\end{tabular}




\begin{tabular}{|c|c|c|}
\hline Human: HeLa cells & ATCC & $\begin{array}{l}\text { Cat\# CCL-2, } \\
\text { RRID: CVCL_0030 }\end{array}$ \\
\hline Human: HeLa $C A V I N 1^{-1-}$ cells & This paper & N/A \\
\hline Human: A431 cells & ATCC & $\begin{array}{l}\text { Cat\# CRL-1555, RRID: } \\
\text { CVCL_0037 }\end{array}$ \\
\hline Human: MCF-7 cells & ATCC & $\begin{array}{l}\text { Cat\# HTB-22, } \\
\text { RRID: CVCL_0031 }\end{array}$ \\
\hline \multicolumn{3}{|l|}{ Experimental Models: Organisms/Stains } \\
\hline Zebrafish: $T A B$ & $\begin{array}{l}\text { University of } \\
\text { Queensland (UQ), } \\
\text { Biological Resources } \\
\text { Aquatics }\end{array}$ & N/A \\
\hline 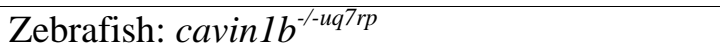 & Current Biology paper & N/A \\
\hline Zebrafish: cavinla ${ }^{- \text {-uqlorp }}$ & This paper & N/A \\
\hline \multicolumn{3}{|l|}{ Oligonucleotides } \\
\hline $\begin{array}{l}\text { Sequence of gRNA targeting human } \\
\text { CAVIN1: GTCAACGTGAAGACCGTGCG }\end{array}$ & This paper & N/A \\
\hline $\begin{array}{l}\text { CRISPR cavinla gene-specific oligo: } \\
\text { TAATACGACTCACTATAGGCCGACAC } \\
\text { AGACTTCAAACGTTTTAGAGCTAGAA } \\
\text { ATAGCAAG }\end{array}$ & This paper & N/A \\
\hline $\begin{array}{l}\text { CRISPR constant oligo: } \\
\text { AAAAGCACCGACTCGGTGCCACTTTTTCA } \\
\text { AGTTGAT } \\
\text { AACGGACTAGCCTTATTTTAACTTGCTATT } \\
\text { TCTAGCT } \\
\text { CTAAAAC }\end{array}$ & Gagnon et al & N/A \\
\hline $\begin{array}{l}\text { HRMA cavinla. Forward: } \\
\text { GCAAGCAGTGTGTGTTAATGG; } \\
\text { Reverse: TTCGGCGAAGATGGCACG }\end{array}$ & This paper & N/A \\
\hline $\begin{array}{l}\text { Sequencing cavinla. Forward: } \\
\text { GGAACCATTCTGCTGTCACC; Reverse: } \\
\text { CCTCATCGTCTCCTCGTCTC }\end{array}$ & This paper & N/A \\
\hline $\begin{array}{l}\text { Real-time PCR primers for human CAVINI. } \\
\text { Forward: TCAACGTGAAGACCGTGC; } \\
\text { Reverse: TGATGCTCAGTTTGGCCG }\end{array}$ & This paper & N/A \\
\hline $\begin{array}{l}\text { Real-time PCR primer for human CAVIN3. } \\
\text { Forward: TCCACGTTCTGCTCTTCAAG; } \\
\text { Reverse: CTCTCCAACTTCGGCCTC }\end{array}$ & This paper & N/A \\
\hline $\begin{array}{l}\text { Real-time PCR primer for human } C A V I . \\
\text { Forward: } \\
\text { CCTTCCTCAGTTCCCTTAAAGC; } \\
\text { Reverse: TGTAGATGTTGCCCTGTTCC }\end{array}$ & This paper & N/A \\
\hline $\begin{array}{l}\text { Real-time PCR primer for human } E H D 2 . \\
\text { Forward: CAACGACCTGGTGAAGAGG; } \\
\text { Reverse: AGATGACGGGCAGTTTGAG }\end{array}$ & This paper & N/A \\
\hline $\begin{array}{l}\text { Real-time PCR primer for human PACSIN2. } \\
\text { Forward: AGCGACCTCATGAACTGC; } \\
\text { Reverse: CATCCAGGCCTTCTCCAC }\end{array}$ & This paper & N/A \\
\hline $\begin{array}{l}\text { Real-time PCR primer for human RORl. } \\
\text { Forward: } \\
\text { AGTGCTGAATTAGTGCCTACC; Reverse: } \\
\text { TTCCCAGAGACTTTGCAGTG }\end{array}$ & This paper & N/A \\
\hline
\end{tabular}




\begin{tabular}{|c|c|c|}
\hline $\begin{array}{l}\text { Real-time PCR primer for human } N Q O 1 . \\
\text { Forward: ATGGTCGGCAGAAGAGC; } \\
\text { Reverse: GGAAATGATGGGATTGAAGT }\end{array}$ & This paper & N/A \\
\hline $\begin{array}{l}\text { Real-time PCR primer for zebrafish cavinla. } \\
\text { Forward: GGACTTGGAGAAGCAAGTGG; } \\
\text { Reverse: TTCAGAGGCA TGCTCTTCCT }\end{array}$ & Lim et al & N/A \\
\hline $\begin{array}{l}\text { Real-time PCR primer for zebrafish cavinlb. } \\
\text { Forward: } \\
\text { AAACGTCTGGAGAGCAACGAGA; } \\
\text { Reverse: GCCACA TTCACTTTCGAACCC }\end{array}$ & Lim et al & N/A \\
\hline $\begin{array}{l}\text { Real-time PCR primer for zebrafish } n q o 1 \text {. } \\
\text { Forward: TGCATGGAAAGAGGGTCGAT; } \\
\text { Reverse: } \\
\text { CTTCTGCGATCAAGCTGAAAGA }\end{array}$ & This paper & N/A \\
\hline \multicolumn{3}{|l|}{ Recombinant DNA } \\
\hline Murine CAVIN1 & (Hill et al., 2008a) & N/A \\
\hline \multicolumn{3}{|l|}{ Deposited Data } \\
\hline Raw data & Mendeley & $\begin{array}{l}\text { Preview at: } \\
\text { https://data.mendeley.com/data } \\
\text { sets/f8w5phmn9k/draft?a=7b2 } \\
\text { e27ab-a25e-4e03-aedf- } \\
\text { 408c195d5aa0 }\end{array}$ \\
\hline \multicolumn{3}{|l|}{ Software } \\
\hline QIAGEN Ingenuity Pathway Analysis & QIAGEN & RRID: SCR_008653 \\
\hline Prism 9 & GraphPad & RRID: SCR_005375 \\
\hline Image $\mathbf{J}$ & $\begin{array}{l}\text { (Schneider, Rasband et } \\
\text { al., 2012) }\end{array}$ & RRID: SCR_003070 \\
\hline
\end{tabular}

\section{Methods and Protocols}

\section{Zebrafish (Danio rerio)}

Zebrafish were raised and maintained according to institutional guidelines (Techniplast recirculating system, 14-h light/ 10-h dark cycle, The University of Queensland). Adults (90 dpf above) were housed in 3 or $8 \mathrm{~L}$ tanks with flow at $28.5^{\circ} \mathrm{C}$, late-larval to juvenile stage zebrafish (6 dpf to $45 \mathrm{dpf}$ ) were housed in $1 \mathrm{~L}$ tanks with flow at $28.5^{\circ} \mathrm{C}$ and embryos (up to $5 \mathrm{dpf})$ were housed in $8 \mathrm{~cm}$ Petri dishes in standard E3 media $(5 \mathrm{mM} \mathrm{NaCl}, 0.17 \mathrm{mM} \mathrm{KCl}$, $0.33 \mathrm{mM} \mathrm{CaCl}_{2}$ and $0.33 \mathrm{mM} \mathrm{MgSO}_{4}$ ) (Westerfield, 2000) at $28.5^{\circ} \mathrm{C}$ (incubated in the dark). All experiments were approved by the University of Queensland (UQ) Animal Ethics committee. The following zebrafish strains were used in this study: wild-type (TAB), an AB/TU line generated by UQ Biological Resources (UQBR) Aquatics, cavin1 $b^{---u q 7 r p}$ (Lim et 
al., 2017), cavinla---uq10rp (this paper) and the cavinla/lb double knockout (DKO) line generated by crossing between the cavinl $a^{-/-u q 10 r p}$ and cavinlb-/-uq7rp lines and incrossing to homozygosity. Only male juvenile and adult zebrafish were used. Zebrafish of developmental stages up to $15 \mathrm{dpf}$ are prior to specific sex determination (Liew \& Orbán, 2014) and the developmental stages are specifically stated in corresponding figure legends. All zebrafish used in this study were healthy, not involved in previous procedures and drug or test naïve. All zebrafish of the same clutch, and sex or developmental stage were randomly allocated into experimental groups.

\section{Cell lines}

All cancer cell lines were purchased from the American Tissue Culture Collection (ATCC) and grown in recommended medium. Specifically, WT HeLa cells, CAVINI KO HeLa cells and A431 cells were grown in Dulbecco's modified Eagle's medium (DMEM) with $10 \%$ (vol/vol) fetal bovine serum (FBS) at $37{ }^{\circ} \mathrm{C}$ in a humidified atmosphere containing $5 \% \mathrm{CO}_{2}$. MCF-7 cell line was subjected to STR profiling (QIMR Berhofer Medical Research Institute) as described previously (McMahon et al., 2019).

\section{Animal handling and reagents}

Zebrafish embryos up to $7 \mathrm{dpf}$ were raised and handled in standard E3 media during experiments ( $5 \mathrm{mM} \mathrm{NaCl}, 0.17 \mathrm{mM} \mathrm{KCl}, 0.33 \mathrm{mM} \mathrm{CaCl} 2,0.33 \mathrm{mM} \mathrm{MgSO} 4)$. All postembryonic zebrafish measurements were carried out between tanks of similar population densities and conditions. All reagents were obtained from Sigma-Aldrich unless otherwise specified.

\section{Generation of CAVIN1 KO cell lines and cavin1a/1b DKO zebrafish}

CAVIN1 KO cell lines were generated using two independent genomic editing methods. A pair of TALENs were designed to generate a double strand break within human CAVINI gene (see DNA binding sequences of TALENs in Key Sources Table) (Fig. EV1A-D). The screening strategies have been previously described (Reljić \& Stroud, 2016).

The CRISPR-Cas9 system was used to generate the second CAVIN1 KO HeLa cell line (Fig. EV1E-G). Cells at $70 \%$ confluency were co-transfected with guide RNA (sgRNA, see sequence in Key Sources Table) targeting CAVIN1 exon 1 region and Cas9 nuclease at a 1:5 
ration ( $\mu \mathrm{g}: \mu \mathrm{g})$ using Lipofectamine Cas9 plus reagent. Vector peGFP/NeoR was additionally transfected for the selection of gRNA positive cells. G418 at $2.0 \mathrm{mg} / \mathrm{ml}$ was added to the medium for selection on the following day. Replace medium every two days using fresh medium with $2.0 \mathrm{mg} / \mathrm{ml} \mathrm{G} 418$ until entire untransfected cells were killed. Transfected cells were then diluted and plated into 96 well plate for single clone isolation using array dilution method as described previously (Hu, Zhang et al., 2016). T7 endonuclease I mismatch assays, DNA sequencing assays, TA clone sequencing assays and immunoblotting were performed to validate the editions in CAVIN1 genes in the cells from different single colony. The clone with homozygous deletion in CAVIN1 ( $\triangle 527-840)$ was identified and selected for this study.

Cavinla/lb DKO line was generated as previously described (Lim et al., 2017). Target site with $>50 \%$ G/C content and no predicted off-target site for zebrafish cavinla (NCBI reference sequence: XM_001920667.5, corresponding Uniprot accession number: E7F0K3) specific sgRNA was selected using the web tool CHOPCHOP (Montague TG, Cruz JM Gagnon etc CHOPCHOP Nucleic Acids Res 42 2014). Synthesis of sgRNA was carried out in a cloning-independent method as adapted from Gagnon et al (Gagnon, Valen et al., 2014) using the cavin1a gene-specific and constant oligos mentioned in the Key Resources Table. Recombinant Cas9 protein containing a nuclear localization signal (PNA Bio Inc) was reconstituted to a solution of $1 \mathrm{mg} / \mathrm{mL}$ Cas9 protein in $20 \mathrm{mM}$ HEPES, $150 \mathrm{mM} \mathrm{KCl}, 1 \%$ sucrose (pH 7.9) and $1 \mathrm{mM}$ DTT. An injection mixture of 700-753 ng/uL Cas9 protein, 200$208 \mathrm{ng} / \mathrm{uL}$ sgRNA and $16 \%$ phenol red was prepared and incubated for $5 \mathrm{~min}$ at room temperature (RT) to allow for Cas9-sgRNA complex formation. Cavin1a-targeting Cas9sgRNA was injected into the cytoplasm of the early one-cell stage WT embryos. Injection volumes were calibrated to approximately $600-800 \mathrm{pL}$ of injection mixture per injection.

Founder rate and percentage of mutant allele in $\mathrm{fl}$ progenies was determined via high resolution melt analysis (HRMA). In the DNA preparation step, for whole-embryo tissue collection, selected $48 \mathrm{hpf}$ embryos were anesthetised by rapid cooling and added into the digestion buffer ( $1 \mathrm{M} \mathrm{KCl}, 1 \mathrm{M} \mathrm{MgCl}_{2}, 1 \mathrm{M}$ Tris $\mathrm{pH} 8.3,10 \% \mathrm{NP} 40,10 \%$ Tween-20, $0.1 \%$ gelatine, $20 \mathrm{mg} / \mathrm{mL}$ Proteinase K). For juvenile zebrafish tissue collection, selected juvenile zebrafish was anesthetised in ethyl 3-aminobenzoate methanesulfonate (tricaine) solution, before cutting an approximately $3 \mathrm{~mm}$ piece of the caudal fin with a sterile razor blade and placing the fin clip in digestion buffer. The mixture was incubated at $60{ }^{\circ} \mathrm{C}$ for $1 \mathrm{~h}$ before reaction termination at $95{ }^{\circ} \mathrm{C}$ for $15 \mathrm{~min}$. Two different HRMA-compatible platforms were 
used (Applied Biosystems ViiA 7 Real-Time PCR System, using the MeltDoctor HRM Master Mix, and Roche LightCycler 480 System, using the LightCycler 480 High Resolution Melting Master). HRMA primers are indicated in the Key Resources Table. When using the LightCycler® 480 System, the high resolution melt (HRM) step was initiated after a standard PCR amplification step. The HRM step consist of a denaturation step at $95{ }^{\circ} \mathrm{C}$, followed by an annealing step at $65{ }^{\circ} \mathrm{C}$. Melt data acquisition began at $65{ }^{\circ} \mathrm{C}$ and ended at $97{ }^{\circ} \mathrm{C}$ with 15 fluorescence readings per degree centigrade at a $0.07{ }^{\circ} \mathrm{C} / \mathrm{s}$ ramp rate. When using the $\mathrm{Vii} \mathrm{A}^{\mathrm{TM}}$ 7 Real-Time PCR System, the HRM step consist of a denaturation step at $95^{\circ} \mathrm{C}$, followed by an annealing step at $60{ }^{\circ} \mathrm{C}$. Melt data acquisition began at $60{ }^{\circ} \mathrm{C}$ and ended at $95{ }^{\circ} \mathrm{C}$ at a $0.025^{\circ} \mathrm{C} / \mathrm{s}$ ramp rate. Stable cavinla f1 mutant zebrafish lines were confirmed using Sanger sequencing with cavinla sequencing primers stated in the Key Resources Table. The selected cavinla line [with protein level change p.(Asp5Leufs*34)], which was designated as cavinla l-uq10rp, was then bred to homozygosity. The cavinla/lb DKO line was generated by crossing the cavin1 $a^{-/-u q 10 r p}$ line to the cavin1 $1 b^{-/-u q 7 r p}$ line (Lim et al 2017) and incrossing the offsprings to homozygosity.

\section{Quantitative mass spectrometry-based comparative proteomic analysis}

Samples were prepared for mass spectrometry and analysed as previously described (Stroud et al., 2016) but with modification for a label free quantification (LFQ) experiment. Briefly, cells were lysed in $1 \%(\mathrm{w} / \mathrm{v})$ sodium deoxycholate, $100 \mathrm{mM}$ Tris- $\mathrm{HCl}(\mathrm{pH} 8.1)$, Tris(2carboxyethy)phosphine (TCEP), $20 \mathrm{mM}$ chloroacetamide and incubated at $99{ }^{\circ} \mathrm{C}$ for $10 \mathrm{~min}$. Reduced and alkylated proteins were digested into peptides using trypsin by incubation at $37^{\circ} \mathrm{C}$ overnight, according to manufacturer's instructions (Promega). Sodium deoxycholate was removed from the peptide mixture using SDB-RPS (Merck) stage-tips made in-house as described (Kulak, Pichler et al., 2014, Stroud et al., 2016). Peptides were reconstituted in $0.1 \%$ trifluoroacetic acid (TFA), $2 \% \mathrm{ACN}$ and analysed by online nano-HPLC/electrospray ionization-MS/MS on a Q Exactive Plus connected to an Ultimate 3000 HPLC (ThermoFisher Scientific). Peptides were loaded onto a trap column (Acclaim C18 PepMap nano Trap x $2 \mathrm{~cm}, 100 \mu \mathrm{m}$ I.D, $5 \mu \mathrm{m}$ particle size and $300 \AA$ pore size; ThermoFisher Scientific) at 15 $\mu \mathrm{L} / \mathrm{min}$ for $3 \mathrm{~min}$ before switching the pre-column in line with the analytical column (Acclaim RSLC C18 PepMap Acclaim RSLC nanocolumn $75 \mu \mathrm{m}$ x 50 cm, PepMap100 C18, $3 \mu \mathrm{m}$ particle size $100 \AA$ pore size; ThermoFisher Scientific). The separation of peptides was performed at $250 \mathrm{~nL} / \mathrm{min}$ using a non-linear ACN gradient of buffer $\mathrm{A}(0.1 \% \mathrm{FA}, 2 \% \mathrm{ACN})$ 
and buffer B $(0.1 \% \mathrm{FA}, 80 \% \mathrm{ACN})$, starting at $2.5 \%$ buffer $\mathrm{B}$ to $35.4 \%$ followed by ramp to $99 \%$ over 278 minutes. Data were collected in positive mode using Data Dependent Acquisition using m/z 375 - 1575 as MS scan range, HCD for MS/MS of the 12 most intense ions with $z \geq 2$. Other instrument parameters were: MS1 scan at 70,000 resolution (at 200 $\mathrm{m} / \mathrm{z}$ ), MS maximum injection time $54 \mathrm{~ms}$, AGC target 3E6, Normalized collision energy was at $27 \%$ energy, Isolation window of $1.8 \mathrm{Da}$, MS/MS resolution 17,500, MS/MS AGC target of 2E5, MS/MS maximum injection time $54 \mathrm{~ms}$, minimum intensity was set at $2 \mathrm{E} 3$ and dynamic exclusion was set to $15 \mathrm{sec}$. Raw files were processed using the MaxQuant platform (Tyanova, Temu et al., 2016a) version 1.6.5.0 using default settings for a label-free experiment with the following changes. The search database was the Uniprot human database containing reviewed canonical sequences (June 2019) and a database containing common contaminants. "Match between runs" was enabled with default settings. Maxquant output (proteinGroups.txt) was processed using Perseus (Tyanova, Temu et al., 2016b) version 1.6.7.0. Briefly, identifications marked "Only identified by site", "Reverse", and "Potential Contaminant" were removed along with identifications made using $<2$ unique peptides. $\log _{2}$ transformed LFQ Intensity values were grouped into control and knockout groups, each consisting of three replicates. Proteins not quantified in at least two replicates from each group were removed from the analysis. Annotations (Gene Ontology (GO), Biological Process (BP), Molecular Function (MF), Cellular Compartment (CC), KEGG, Corum and PFAM) were loaded through matching database built into Perseus with the majority protein ID. A two-sample, two-sided t-test was performed on the values with significance determined using permutation-based FDR statistics (FDR $<1 \%, \mathrm{~S} 0=1.5)$ to determine differentially expressed proteins. Pathway analysis (Table EV2; Fig. 1D) and upstream regulator analysis (URA) (Table 1; Fig. 1E) were performed on significantly altered (FDR $<1 \%$, s0=1.5) proteins in CAVIN1 KO cells using the "core analysis" function included in the Ingenuity Pathway Analysis (IPA) software (QIAGEN Bioinformatics, content version 44691306) (Krämer, Green et al., 2013). Overlap p-value in URA measures the significance between the dataset genes and the genes that are regulated by a transcriptional regulator. It is calculated using Fisher's Exact Test and significance is generally attributed to $p$-values $<0.01$.

\section{SDS PAGE and western blot analysis}

Cell lysates were determined using a BCA Protein Assay Kit as the standard. Estimated proteins $(20-40 \mu \mathrm{g})$ were separated by SDS PAGE and transferred to PVDF membranes. 
Western blots were performed as standard procedures. Detection and quantification of target proteins was carried out on a scanning system (BIO-RAD, ChemiDoc ${ }^{\mathrm{TM}}$ MP) using horseradish peroxidase (HRP)-conjugated secondary antibodies and ECL detection reagent. Intensities of bands were quantitated by ImageJ 2.0 software.

\section{Proximity ligation assay}

Duolink II Detection Kit was utilized to assess protein-protein proximity according to the manufacturer's instruction. Primary antibodies with different species were used for the detection of each protein pair. Specifically, Rabbit anti-NRF2 (Abcam) and mouse antiUbiquitin (Sapphire Bioscience) for PLA in Fig. 3I and J; Rabbit anti-CAVIN1(rabbit, Proteintech) and mouse anti-NRF2 (Abcam) for PLA in Fig. 4J and T. PLA signals were visualized and imaged by Zeiss LSM 880 confocal microscope and quantified using ImageJ 2.0 software.

\section{Immunofluorescence}

Cells were plated onto glass coverslips at $70 \%$ confluence and then fixed in $4 \%$ (vol/vol) paraformaldehyde in PBS for $15 \mathrm{~min}$ at RT after the indicated treatments. Coverslips were washed three times in PBS and permeabilized in $0.1 \%$ (vol/vol) Triton X-100 in PBS for 5 min and blocked in 1\% (vol/vol) BSA in PBS for $30 \mathrm{~min}$ at RT. Primary antibodies were diluted in 1\% BSA/PBS solution at optimized concentrations and incubated with coverslips for at $4^{\circ} \mathrm{C}$ overnight. Diluted secondary antibodies (1:500 in $\left.1 \% \mathrm{BSA} / \mathrm{PBS}\right)$ conjugated with fluorescent dyes were later added onto coverslips and incubated for $1 \mathrm{~h}$. Coverslips were washed in PBS for three times and mounted in Mowiol in $0.2 \mathrm{M}$ Tris- $\mathrm{HCl} \mathrm{pH} \mathrm{8.5.} \mathrm{The}$ images were taken on Zeiss LSM 880 confocal microscope and intensities of fluorescence were quantitated using ImageJ 2.0.

\section{Co-immunoprecipitation assay}

HeLa cells were seeded in 10-cm dishes ( 1 x $10^{6}$ cells per dish) and lysed in ice-cold lysis buffer (20 mM Tris-HCl, pH 7.4, $150 \mathrm{mM} \mathrm{NaCl,} \mathrm{10 \%} \mathrm{Glycerol,} \mathrm{1 \%} \mathrm{Triton} \mathrm{X-100,}$ cOmplete $^{\mathrm{TM}}$ protease inhibitor cocktail tablet from Roche and a PhosSTOP tablet from Roche). Lysates containing 500-1000 $\mu$ g protein (made up to $500 \mu \mathrm{l}$ by lysis buffer) was precleared using protein A-coupled sepharose beads $(20 \mathrm{ul})$. After centrifuging at 2,500 $\mathrm{g}$ for 1 min, supernatants were collected and mixed with $1.5 \mu \mathrm{g}$ rabbit anti-NRF2 antibody (Abcam) 
or rabbit anti-CAVIN1 antibody (Abcam). Rabbit anti-IgG $(1.5 \mu \mathrm{g} / 500 \mu \mathrm{l})$ was used as negative control. Incubate the lysates with antibodies over night at $4{ }^{\circ} \mathrm{C}$ and protein $\mathrm{A}(20 \mu \mathrm{l})$ was added for another $3 \mathrm{~h}$ incubation. The tubes were centrifuged and the supernatant was removed from the beads. After the beads were washed with lysis buffer for three times, sample buffer was added to denature the samples by boiling it at $95{ }^{\circ} \mathrm{C}$ for $10 \mathrm{~min}$. Western blot analysis was applied to detect the proteins that co-immunoprecipitated with NRF2 or CAVIN1.

\section{RNA preparation, reverse-transcription and quantitative real-time PCR}

For human cell lines, total RNA was extracted using QIAGEN RNA isolation kit following the manufacturer's instructions and measured using a NanoDrop spectrophotometer (ThermoFisher Scientific). Two-step reverse transcription was conducted to access single strand cDNA using SuperscriptIII reverse transcriptase (ThermoFisher Scientific) as per manufacturer's instruction. SYBR-Green PCR Mater Mix or Taqman (CAVIN1 probe) was utilized for real-time PCR using a ViiA7 Real-time PCR system (ThermoFisher Scientific). The sequence of oligonucleotide primers for real-time PCR are listed in Key Resources Table. Gene expression was analysed using the delta-delta $\mathrm{Ct}$ method as previously described (Pearen, Eriksson et al., 2012).

For zebrafish, RNA was isolated from cavin1a/1b DKO and WT zebrafish embryos (> 100 embryos randomly selected from 1 clutch) using the RNeasy Mini Kit (QIAGEN) and cDNA synthesis was performed using SuperscriptIII reverse transcriptase (ThermoFisher Scientific) as per manufacturer's instructions. Quantitative real-time PCR was performed using the SYBR Green PCR Master Mix on a ViiA7 Real-time PCR system (ThermoFisher Scientific) according to manufacturer's instructions with 3 biological replicates (embryos randomly selected from 3 clutches) and 3 technical replicates on 96-well plates. Primers used were detailed in the Key Resources Table. Gene expression was analyzed using the delta-delta $\mathrm{Ct}$ method as previously described (Pearen et al., 2012).

\section{Live imaging of zebrafish embryos}

Prior to imaging, zebrafish (up to $26 \mathrm{dpf}$ ) were anesthetized in tricaine solution in E3, mounted in $1 \%$ low melting point (LMP) agarose on MatTek glass bottom dishes in a lateral view unless otherwise stated (anterior to the left, posterior to the right) and submerged in 
tricaine solution. The embryos were submerged in tricaine solution in E3 throughout all imaging periods.

For stereo microscopy of general morphology, zebrafish embryos were mounted as described above and imaged under a SMZ1500 stereomicroscope. For fluorescence stereo microscopy, zebrafish embryos were mounted as described above and imaged under a Nikon SMZ18 stereo microscope.

For live confocal images of WT and cavinla/lb DKO zebrafish, embryos were incubated at $28^{\circ} \mathrm{C}$ and mounted in LMP agarose as above and imaged under a Zeiss LSM880 confocal microscope. For general characterization of zebrafish, WT and cavinla/lb DKO embryos were preincubated in BODIPY FL C5-Ceramide (ThermoFisher Scientific) for $24 \mathrm{~h}$ (at 28 ${ }^{\circ} \mathrm{C}$ ) s previously described (Lim, Lo et al., 2020) before the anaesthesia and mounting steps detailed above.

\section{Body length measurement of live zebrafish}

Images captured using the NIS Elements Version 4.20 software on the SMZ1500 stereomicroscope were used to measure the body length of $3 \mathrm{dpf}$ WT and cavinla/lb DKO zebrafish embryos. Body length was defined as the region from the tip of the anterior end of the embryo to the end of the trunk before the caudal fin. Measurements were conducted using Fiji and were non-blind. Embryos were randomly selected from 3 biological replicates (clutches) with no prior formal sample-size estimation.

\section{Reactive oxygen species (ROS) detection}

The cell-permeant reagent H2DCFDA (2', 7'-dichlorodihydrofluorescein diacetate) (Thermo Fisher Scientific) was employed to represent the ROS levels in HeLa cells. Cells were lysed after incubation with reagent $(20 \mu \mathrm{M})$ for $30 \mathrm{~min}$ at $37^{\circ} \mathrm{C}$. Cell lysates of untreated $\mathrm{or}_{2} \mathrm{O}_{2}$ treated HeLa cells containing equal protein $(100 \mu \mathrm{g})$ were diluted to $15 \mu \mathrm{l}$ working volume and loaded into a flat-bottom white 384 well plate, which was then applied to a top-read microplate reader (Bio-Tek) for the quantification of fluorescence (Excitation/Emission in nm: 485/528). Fluorescence values for each group were corrected by subtracting background fluorescence value generated by a cell lysis buffer alone control. ROS were also labelled by CellROX Green probe (Thermo Fisher Scientific) and visualized as green fluorescence in 
mounted cultures by Zeiss LSM 880 confocal microscope on $63 x$ oil objective lens.

\section{Lipid peroxidation detection}

Lipid peroxidation in cells with were detected using Image-iT lipid peroxidation kit (ThermoFisher) according to the manufacturer's instruction. For the inhibition of lipid peroxidation, cells were pre-treated with $\alpha$-Tocopherol for $30 \min$ at $25 \mu \mathrm{M}$ as this concentration of $\alpha$-Tocopherol most effectively protected lipids from oxidant attack (Fig. EV3J). BODIPY-C11 fluorescence was visualised in live cells by Zeiss LSM 880 confocal microscope on $63 x$ oil objective lens.

\section{ROS assessment in zebrafish embryos}

2 dpf zebrafish were incubated in $2 \mathrm{mM} \mathrm{H}_{2} \mathrm{O}_{2}$ for $1 \mathrm{~h}$, washed in E3 media 3 times and stained using H2DCFDA ( $20 \mu \mathrm{M}$ in E3 media) for $30 \mathrm{~min}$. The embryos were then washed with E3 media 2 times, anesthetized in tricaine and mounted in 1\% LMP agarose on $35 \mathrm{~mm}$ MatTek glass bottom dishes for imaging under a Zeiss LSM880 confocal microscope or Nikon SMZ18 stereo microscope. To quantitate, stereo microscope images of treated and untreated zebrafish were analysed using Fiji. The lookup table of the images were inverted for visualization of embryo somite segments. For each embryo, a constant area of 4 somite pairs at the end of the embryo yolk extension was analyzed and the corrected total fluorescence (integrated density - [area of selection * mean grey value of image background]) was calculated. DCF fluorescence of individual $\mathrm{H}_{2} \mathrm{O}_{2}$-treated zebrafish was normalized using the mean corrected total fluorescence of its corresponding untreated clutch.

\section{Hydrogen peroxide scavenging assay}

Cell lysate containing $2 \mathrm{mg}$ protein in $1.5 \mathrm{~mL}$ distilled $\mathrm{H}_{2} \mathrm{O}$ were incubated with $62.5 \mu \mathrm{H}_{2} \mathrm{O}_{2}$ $(5 \mathrm{mM})$ at $37^{\circ} \mathrm{C}$ for $15 \mathrm{~min}$ to allow redox reaction to occur. Next, $0.25 \mathrm{~mL}$ ammonium iron (II) sulphate hexahydrate $(1 \mathrm{mM})$ was added to reaction solution for another $5 \mathrm{~min}$

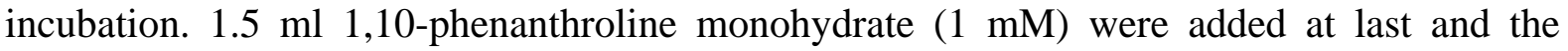
amount of tri-phenanthroline complex that formed by ferrous and phenanthroline were indicated by optical density value that measured at $510 \mathrm{~nm}$. hydrogen peroxide scavenging activity was calculated using following formula: 


$$
\% \mathrm{H}_{2} \mathrm{O}_{2} \text { scavenging activity }=\frac{\text { Atest }}{\text { Ablank }} \times 100
$$

$A_{\text {blank }}$ is the absorbance of solution containing only ferrous ammonium sulphate and 1,10 phenanthroline.

\section{Cell viability assay}

Cells were counted using a hemocytometer and seeded into 96-well plate at 5000 cells in 90 $\mu \mathrm{l}$ medium per well. After 6, 12, 24, 48 and $72 \mathrm{~h}$ incubation, $10 \mu \mathrm{l}$ of PrestoBlue ${ }^{\mathrm{TM}}$ Viability Reagent (10x) (absorbance wavelength: $600 \mathrm{~nm}$ ) (Thermo Fisher Scientific Inc.), which was quickly converted by viable cells to a red fluorescence reduced form of the dye possessing an absorbance at $570 \mathrm{~nm}$, was added into each well and incubated for $30 \mathrm{~min}$. Both absorbance value at $570 \mathrm{~nm}$ and $600 \mathrm{~nm}$ were measured for each plate, where $570 \mathrm{~nm}$ was used as experimental wavelength and $600 \mathrm{~nm}$ as normalization wavelength. The absorbance values for wells only containing medium without cells were read for background correction. Raw data was processed to evaluate the percent reduction of PrestoBlue ${ }^{\mathrm{TM}}$ reagent for each well by using the following equation referring to the manufacturer's protocol:

$$
\% \text { Reduction of PrestoBlue }{ }^{\mathrm{TM}} \text { Reagent }=\frac{(117216 \times A 1)-(80586 \times A 2)}{(155677 \times N 2)-(14652 \times N 1)} \times 100
$$

Where: A1 = Absorbance of test wells at $570 \mathrm{~nm}, \mathrm{~A} 2=$ Absorbance of test wells at $600 \mathrm{~nm}$, $\mathrm{N} 1$ = Absorbance of media only wells at $570 \mathrm{~nm}, \mathrm{~N} 2=$ Absorbance of media only wells at $600 \mathrm{~nm}$.

\section{Live-cell imaging and laser treatment}

HeLa cells were plated to $35-\mathrm{mm}$ glass bottom dishes the day before imaging. $\mathrm{CO}_{2}$ independent medium (Gibco) containing 10\% FBS was applied on cells to remain the cell viability. Cells were incubated with C11-BODIPY probes for $30 \mathrm{~min}$ for lipid labelling prior to imaging. Zeiss LSM 880 confocal microscope with Airyscan was utilised for imaging. After $405 \mathrm{~nm}$ laser pulses applied to cells, FITC and Texas Red channels were used to collect images over $80 \mathrm{sec}$ with $1 \mathrm{sec}$ interval time. Image analysis was performed using Image $\mathbf{J}$ 2.0. ROIs were done and imported from Zeiss Zen 2012 Black to locate laser-treated region. 


\section{Nile red vital staining of zebrafish juveniles}

Live $26 \mathrm{dpf}$ WT and cavinl/alb DKO juvenile zebrafish were incubated in system water supplemented with Nile Red stock $(1.5 \mathrm{mg} / \mathrm{mL}$ Nile Red in acetone) to a working concentration of $0.4 \mu \mathrm{g} / \mathrm{mL}$ in the dark for $35 \mathrm{~min}$. Zebrafish were then anesthetized in tricaine, washed for $1 \mathrm{~min}$ in tricaine solution, mounted in 3\% LMP agarose on a $35 \mathrm{~mm}$ petri dish and imaged under a Zeiss LSM 510 Meta inverted confocal microscope.

\section{Electron microscopy of adult zebrafish}

This protocol is a modified version originally by Deerinck et al. and designed to enhance membrane contrast using reduced osmium tetroxide, thiocarbohydrazide-osmium, uranyl acetate and en bloc lead nitrate staining. A solution containing $2.5 \%$ glutaraldehyde in $2 \mathrm{X}$ PBS was added to the dish in equal volume with dissected adult zebrafish tissues and placed for $5 \mathrm{~min}$ in a Pelco Biowave under vacuum and irradiated at $80 \mathrm{~W}$. Dissected adult tissues were then irradiated in fresh fixative ( $2.5 \%$ glutaraldehyde), under vacuum, for a further 6 min. Embryos or adult tissues were washed $4 \times 2$ min in $0.1 \mathrm{M}$ cacodylate buffer. A solution containing both potassium ferricyanide (1.5\%) and osmium tetroxide (2\%) in $0.1 \mathrm{M}$ cacodylate buffer was prepared and samples immersed for $30 \mathrm{~min}$ at RT. Following 6 x 3 min washes in distilled water, samples were then incubated in a filtered solution containing thiocarbohydrazide (1\%) for $30 \mathrm{~min}$ at RT. After subsequent washing in distilled water $(6 \times 2$ min), samples were incubated in an aqueous solution of osmium tetroxide (2\%) for $30 \mathrm{~min}$. Samples were washed again in distilled water (6 x 2 min) and incubated in $1 \%$ uranyl acetate (aqueous) for $30 \mathrm{~min}$ at $4^{\circ} \mathrm{C}$. Further distilled water washes $(2 \times 2 \mathrm{~min})$ were completed before adding a freshly prepared filtered $0.06 \%$ lead nitrate in aspartic acid $(\mathrm{pH} 5.5)$ solution warmed to $60^{\circ} \mathrm{C}$. The lead nitrate solution containing tissue blocks was further incubated for $20 \mathrm{~min}$ at $60^{\circ} \mathrm{C}$ before rinsing in distilled water (6 x $3 \mathrm{~min}$ ) at RT. Samples were dehydrated twice in each ethanol solution of 30\%, 50\%, 70\%, $90 \%$ and $100 \%$ absolute ethanol for $40 \mathrm{~s}$ at 250 watt in the Pelco Biowave. Epon LX112 resin was used for embedding the tissue with infiltration steps at $25 \%, 50 \%, 75 \%$ resin to ethanol in the Pelco Biowave under vacuum at 250 watt for 3 min and finishing with $100 \%$ resin (twice), before the final resin embedding and placed in a 60 oC oven for 12 hours. Blocks were sectioned on a Leica UC64 ultramicrotome at $60 \mathrm{~nm}$ and mounted on formvar coated 3 slot $\mathrm{Cu}$ grids. Thin sections (60 $\mathrm{nm}$ ) were viewed on a Jeol JEM-1011 at $80 \mathrm{kV}$. 


\section{Quantification and Statistical Analysis}

PRISM software version 9.0 was used for statistical analysis. Significance was assessed by using independent two-tailed Student's $t$-test or analysis of variance (ANOVA) as indicated in figure legends. Quantified values are presented as mean \pm SD from at least three independent experiments. $P$-values equal to or lower than 0.05 were considered as statistically significant, and the actual $p$-values are reported in the figures. If the $p$-value is less than 0.0001 , we report “****" in the figures. All of the statistical details of experiments can be found in the figure legends. 


\section{Acknowledgments}

This work was supported by the National Health and Medical Research Council of Australia (grants APP1140064 and APP1150083 and fellowship APP1156489 to R.G.P.; grants APP1125390, APP1140906 to M.T.R. and D.A.S.; fellowship APP1140851 to D.A.S.).

R.G.P. is supported by the Australian Research Council (ARC) Centre of Excellence in Convergent Bio-Nano Science and Technology. The authors acknowledge the use of the Microscopy Australia Research Facility at the Center for Microscopy and Microanalysis at The University of Queensland. Confocal microscopy was performed at the Australian Cancer Research Foundation (ACRF)/Institute for Molecular Bioscience (IMB) Dynamic Imaging Facility for Cancer Biology with funding from the ACRF. We thank the Monash FlowCore and the Monash University Biomedical Proteomics Facility for the provision of instrumentation, training, and technical support.

\section{Author Contributions}

Conceptualization, Y.W., K.A.M and R.G.P.; Methodology, Y.W., Y.-W.L. and D.A.S.; Formal Analysis, Y.W., Y.-W.L. and D.A.S; Writing - Original Draft, Y.W., Y.-W.L., D.A.S, K.A.M. and R.G.P.; Writing - Review \& Editing, Y.W., K.A.M., R.G.P. Y.-W.L., H.P.L., T.E.H, M.T.R. and D.A.S.; Supervision, Y.W., K.A.M., R.G.P.; Funding Acquisition, R.G.P., M.T.R., D.A.S.

\section{Conflicts of Interests}

The authors declare no competing interests. 
bioRxiv preprint doi: https://doi.org/10.1101/2021.06.09.447684; this version posted June 9, 2021. The copyright holder for this preprint (which was not certified by peer review) is the author/funder. All rights reserved. No reuse allowed without permission.

\section{References}

Bastiani M, Liu L, Hill MM, Jedrychowski MP, Nixon SJ, Lo HP, Abankwa D, Luetterforst R, Fernandez-Rojo M, Breen MR, Gygi SP, Vinten J, Walser PJ, North KN, Hancock JF, Pilch PF, Parton RG (2009) MURC/Cavin-4 and cavin family members form tissue-specific caveolar complexes. The Journal of cell biology 185: 1259-1273

Byrne DP, Dart C, Rigden DJ (2012) Evaluating Caveolin Interactions: Do Proteins Interact with the Caveolin Scaffolding Domain through a Widespread Aromatic Residue-Rich Motif? PloS one 7: e44879

Cheng JP, Mendoza-Topaz C, Howard G, Chadwick J, Shvets E, Cowburn AS, Dunmore BJ, Crosby A, Morrell NW, Nichols BJ (2015) Caveolae protect endothelial cells from membrane rupture during increased cardiac output. The Journal of cell biology 211: 53-61

Collins BM, Davis MJ, Hancock JF, Parton RG (2012) Structure-based reassessment of the caveolin signaling model: do caveolae regulate signaling through caveolin-protein interactions? Developmental cell 23: 11-20

Conti E, Izaurralde E (2005) Nonsense-mediated mRNA decay: molecular insights and mechanistic variations across species. Current Opinion in Cell Biology 17: 316-325

Couet J, Li S, Okamoto T, Ikezu T, Lisanti MP (1997) Identification of peptide and protein ligands for the caveolin-scaffolding domain. Implications for the interaction of caveolin with caveolaeassociated proteins. The Journal of biological chemistry 272: 6525-33

Dhakshinamoorthy S, Jaiswal AK (2001) Functional characterization and role of INrf2 in antioxidant response element-mediated expression and antioxidant induction of $\mathrm{NAD}(\mathrm{P}) \mathrm{H}$ :quinone oxidoreductase1 gene. Oncogene 20: 3906-17

Dodson M, Castro-Portuguez R, Zhang DD (2019) NRF2 plays a critical role in mitigating lipid peroxidation and ferroptosis. Redox Biol 23: 101107

El-Kenawi A, Ruffell B (2017) Inflammation, ROS, and Mutagenesis. Cancer Cell 32: 727-729

Fourquet S, Guerois R, Biard D, Toledano MB (2010) Activation of NRF2 by nitrosative agents and $\mathrm{H} 2 \mathrm{O} 2$ involves KEAP1 disulfide formation. The Journal of biological chemistry 285: 8463-71

Gagnon JA, Valen E, Thyme SB, Huang P, Akhmetova L, Pauli A, Montague TG, Zimmerman S, Richter C, Schier AF (2014) Efficient mutagenesis by Cas9 protein-mediated oligonucleotide insertion and large-scale assessment of single-guide RNAs. PloS one 9: e98186

Gambin Y, Ariotti N, McMahon K-A, Bastiani M, Sierecki E, Kovtun O, Polinkovsky ME, Magenau A, Jung W, Okano S, Zhou Y, Leneva N, Mureev S, Johnston W, Gaus K, Hancock JF, Collins BM, Alexandrov K, Parton RG (2014) Single-molecule analysis reveals self assembly and nanoscale segregation of two distinct cavin subcomplexes on caveolae. eLife 3: e01434

Hayashi YK, Matsuda C, Ogawa M, Goto K, Tominaga K, Mitsuhashi S, Park YE, Nonaka I, HinoFukuyo N, Haginoya K, Sugano H, Nishino I (2009) Human PTRF mutations cause secondary deficiency of caveolins resulting in muscular dystrophy with generalized lipodystrophy. J Clin Invest 119: 2623-33

Hayer A, Stoeber M, Bissig C, Helenius A (2010) Biogenesis of caveolae: stepwise assembly of large caveolin and cavin complexes. Traffic (Copenhagen, Denmark) 11: 361-82

Hill MM, Bastiani M, Luetterforst R, Kirkham M, Kirkham A, Nixon SJ, Walser P, Abankwa D, Oorschot VM, Martin S, Hancock JF, Parton RG (2008a) PTRF-Cavin, a conserved cytoplasmic protein required for caveola formation and function. Cell 132: 113-24 
bioRxiv preprint doi: https://doi.org/10.1101/2021.06.09.447684; this version posted June 9, 2021. The copyright holder for this preprint (which was not certified by peer review) is the author/funder. All rights reserved. No reuse allowed without permission.

Hill MM, Bastiani M, Luetterforst R, Kirkham M, Kirkham A, Nixon SJ, Walser P, Abankwa D, Oorschot VMJ, Martin S, Hancock JF, Parton RG (2008b) PTRF-Cavin, a Conserved Cytoplasmic Protein Required for Caveola Formation and Function. Cell 132: 113-124

Hirama T, Das R, Yang Y, Ferguson C, Won A, Yip CM, Kay JG, Grinstein S, Parton RG, Fairn GD (2017) Phosphatidylserine dictates the assembly and dynamics of caveolae in the plasma membrane. The Journal of biological chemistry 292: 14292-14307

Hu P, Zhang W, Xin H, Deng G (2016) Single Cell Isolation and Analysis. Front Cell Dev Biol 4: 116-116

Inder KL, Ruelcke JE, Petelin L, Moon H, Choi E, Rae J, Blumenthal A, Hutmacher D, Saunders NA, Stow JL, Parton RG, Hill MM (2014) Cavin-1/PTRF alters prostate cancer cell-derived extracellular vesicle content and internalization to attenuate extracellular vesicle-mediated osteoclastogenesis and osteoblast proliferation. Journal of extracellular vesicles 3

Jung W, Sierecki E, Bastiani M, O'Carroll A, Alexandrov K, Rae J, Johnston W, Hunter DJB, Ferguson C, Gambin Y, Ariotti N, Parton RG (2018) Cell-free formation and interactome analysis of caveolae. Journal of Cell Biology 217: 2141-2165

Kansanen E, Kuosmanen SM, Leinonen H, Levonen A-L (2013) The Keap1-Nrf2 pathway: Mechanisms of activation and dysregulation in cancer. Redox Biology 1: 45-49

Kovtun O, Tillu VA, Jung W, Leneva N, Ariotti N, Chaudhary N, Mandyam RA, Ferguson C, Morgan GP, Johnston WA, Harrop SJ, Alexandrov K, Parton RG, Collins BM (2014) Structural insights into the organization of the cavin membrane coat complex. Developmental cell 31: 405-19

Krämer A, Green J, Pollard J, Jr, Tugendreich S (2013) Causal analysis approaches in Ingenuity Pathway Analysis. Bioinformatics 30: 523-530

Kulak NA, Pichler G, Paron I, Nagaraj N, Mann M (2014) Minimal, encapsulated proteomic-sample processing applied to copy-number estimation in eukaryotic cells. Nat Methods 11: 319-24

Lee JH, Byun DS, Lee MG, Ryu BK, Kang MJ, Chae KS, Lee KY, Kim HJ, Park H, Chi SG (2008) Frequent epigenetic inactivation of hSRBC in gastric cancer and its implication in attenuated p53 response to stresses. International journal of cancer Journal international du cancer 122: 1573-84

Li J, Cao F, Yin H-1, Huang Z-j, Lin Z-t, Mao N, Sun B, Wang G (2020) Ferroptosis: past, present and future. Cell Death \& Disease 11: 88

Liew WC, Orbán L (2014) Zebrafish sex: a complicated affair. Brief Funct Genomics 13: 172-87

Lim Y-W, Lo HP, Hall TE, Parton RG (2020) Live Confocal Imaging of Zebrafish Notochord Cells Under Mechanical Stress In Vivo. In Caveolae: Methods and Protocols, Blouin CM (ed) pp 175187. New York, NY: Springer US

Lim YW, Lo HP, Ferguson C, Martel N, Giacomotto J, Gomez GA, Yap AS, Hall TE, Parton RG (2017) Caveolae Protect Notochord Cells against Catastrophic Mechanical Failure during Development. Current biology : CB 27: 1968-1981.e7

Liu L, Pilch PF (2008) A critical role of cavin (polymerase I and transcript release factor) in caveolae formation and organization. The Journal of biological chemistry 283: 4314-22

Liu L, Pilch PF (2016) PTRF/Cavin-1 promotes efficient ribosomal RNA transcription in response to metabolic challenges. eLife 5: e17508

Lo HP, Nixon SJ, Hall TE, Cowling BS, Ferguson C, Morgan GP, Schieber NL, Fernandez-Rojo MA, Bastiani M, Floetenmeyer M, Martel N, Laporte J, Pilch PF, Parton RG (2015) The caveolin-cavin system plays a conserved and critical role in mechanoprotection of skeletal muscle. The Journal of cell biology 210: 833-49

McMahon K-A, Wu Y, Gambin Y, Sierecki E, Tillu VA, Hall T, Martel N, Okano S, Moradi SV, Ruelcke JE, Ferguson C, Yap AS, Alexandrov K, Hill MM, Parton RG (2019) Identification of 
bioRxiv preprint doi: https://doi.org/10.1101/2021.06.09.447684; this version posted June 9, 2021. The copyright holder for this preprint (which was not certified by peer review) is the author/funder. All rights reserved. No reuse allowed without permission.

intracellular cavin target proteins reveals cavin-PP1alpha interactions regulate apoptosis. Nature Communications 10: 3279

Milkovic L, Cipak Gasparovic A, Cindric M, Mouthuy P-A, Zarkovic N (2019) Short Overview of ROS as Cell Function Regulators and Their Implications in Therapy Concepts. Cells 8: 793

Moon H, Lee CS, Inder KL, Sharma S, Choi E, Black DM, Le Cao KA, Winterford C, Coward JI, Ling MT, Craik DJ, Parton RG, Russell PJ, Hill MM (2014) PTRF/cavin-1 neutralizes noncaveolar caveolin-1 microdomains in prostate cancer. Oncogene 33: 3561-70

Mukhopadhyay D, Dasgupta P, Sinha Roy D, Palchoudhuri S, Chatterjee I, Ali S, Ghosh Dastidar S (2015) A Sensitive In vitro Spectrophotometric Hydrogen Peroxide Scavenging Assay using 1,10Phenanthroline. Free Radicals and Antioxidants 6: 124-132

Nassar ZD, Moon H, Duong T, Neo L, Hill MM, Francois M, Parton RG, Parat MO (2013) PTRF/Cavin-1 decreases prostate cancer angiogenesis and lymphangiogenesis. Oncotarget 4: 1844-55

Ni Y, Eng C (2012) Vitamin E protects against lipid peroxidation and rescues tumorigenic phenotypes in cowden/cowden-like patient-derived lymphoblast cells with germline SDHx variants. Clinical cancer research : an official journal of the American Association for Cancer Research 18: 495461

Parton RG, del Pozo MA (2013) Caveolae as plasma membrane sensors, protectors and organizers. Nature reviews Molecular cell biology 14: 98-112

Parton RG, Hanzal-Bayer M, Hancock JF (2006) Biogenesis of caveolae: a structural model for caveolin-induced domain formation. Journal of Cell Science 119: 787

Parton RG, Kozlov MM, Ariotti N (2020a) Caveolae and lipid sorting: Shaping the cellular response to stress. Journal of Cell Biology 219

Parton RG, McMahon KA, Wu Y (2020b) Caveolae: Formation, dynamics, and function. Curr Opin Cell Biol 65: 8-16

Pearen MA, Eriksson NA, Fitzsimmons RL, Goode JM, Martel N, Andrikopoulos S, Muscat GEO (2012) The nuclear receptor, Nor-1, markedly increases type II oxidative muscle fibers and resistance to fatigue. Mol Endocrinol 26: 372-384

Perl A, Qian Y, Chohan KR, Shirley CR, Amidon W, Banerjee S, Middleton FA, Conkrite KL, Barcza M, Gonchoroff N, Suarez SS, Banki K (2006) Transaldolase is essential for maintenance of the mitochondrial transmembrane potential and fertility of spermatozoa. Proceedings of the National Academy of Sciences 103: 14813

Pickering AM, Koop AL, Teoh CY, Ermak G, Grune T, Davies KJ (2010) The immunoproteasome, the $20 \mathrm{~S}$ proteasome and the PA28 $\alpha \beta$ proteasome regulator are oxidative-stress-adaptive proteolytic complexes. Biochem J 432: 585-94

Pickering AM, Staab TA, Tower J, Sieburth D, Davies KJ (2013) A conserved role for the 20S proteasome and Nrf2 transcription factor in oxidative stress adaptation in mammals, Caenorhabditis elegans and Drosophila melanogaster. J Exp Biol 216: 543-53

Recktenwald CV, Kellner R, Lichtenfels R, Seliger B (2008) Altered Detoxification Status and Increased Resistance to Oxidative Stress by K-Ras Transformation. Cancer Research 68: 10086

Reljić B, Stroud DA (2016) Screening Strategies for TALEN-Mediated Gene Disruption. Methods Mol Biol 1419: 231-52

Riegman M, Sagie L, Galed C, Levin T, Steinberg N, Dixon SJ, Wiesner U, Bradbury MS, Niethammer P, Zaritsky A, Overholtzer M (2020) Ferroptosis occurs through an osmotic mechanism and propagates independently of cell rupture. Nature Cell Biology 22: 1042-1048 
bioRxiv preprint doi: https://doi.org/10.1101/2021.06.09.447684; this version posted June 9, 2021. The copyright holder for this preprint (which was not certified by peer review) is the author/funder. All rights reserved. No reuse allowed without permission.

Roh J-L, Kim EH, Jang H, Shin D (2017) Nrf2 inhibition reverses the resistance of cisplatin-resistant head and neck cancer cells to artesunate-induced ferroptosis. Redox Biology 11: 254-262

Schneider CA, Rasband WS, Eliceiri KW (2012) NIH Image to ImageJ: 25 years of image analysis. Nature Methods 9: 671-675

Shin D, Kim EH, Lee J, Roh J-L (2018) Nrf2 inhibition reverses resistance to GPX4 inhibitor-induced ferroptosis in head and neck cancer. Free Radical Biology and Medicine 129: 454-462

Sinha B, Koster D, Ruez R, Gonnord P, Bastiani M, Abankwa D, Stan RV, Butler-Browne G, Vedie B, Johannes L, Morone N, Parton RG, Raposo G, Sens P, Lamaze C, Nassoy P (2011) Cells respond to mechanical stress by rapid disassembly of caveolae. Cell 144: 402-13

Stroud DA, Surgenor EE, Formosa LE, Reljic B, Frazier AE, Dibley MG, Osellame LD, Stait T, Beilharz TH, Thorburn DR, Salim A, Ryan MT (2016) Accessory subunits are integral for assembly and function of human mitochondrial complex I. Nature 538: 123-126

Sui X, Zhang R, Liu S, Duan T, Zhai L, Zhang M, Han X, Xiang Y, Huang X, Lin H, Xie T (2018) RSL3 Drives Ferroptosis Through GPX4 Inactivation and ROS Production in Colorectal Cancer. Front Pharmacol 9: 1371

Syu J-P, Chi J-T, Kung H-N (2016) Nrf2 is the key to chemotherapy resistance in MCF7 breast cancer cells under hypoxia. Oncotarget 7: 14659-14672

Tillu VA, Lim YW, Kovtun O, Mureev S, Ferguson C, Bastiani M, McMahon KA, Lo HP, Hall TE, Alexandrov K, Collins BM, Parton RG (2018) A variable undecad repeat domain in cavin1 regulates caveola formation and stability. EMBO reports 19

Tyanova S, Temu T, Cox J (2016a) The MaxQuant computational platform for mass spectrometrybased shotgun proteomics. Nat Protoc 11: 2301-2319

Tyanova S, Temu T, Sinitcyn P, Carlson A, Hein MY, Geiger T, Mann M, Cox J (2016b) The Perseus computational platform for comprehensive analysis of (prote)omics data. Nat Methods 13: 731-40

Ubellacker JM, Tasdogan A, Ramesh V, Shen B, Mitchell EC, Martin-Sandoval MS, Gu Z, McCormick ML, Durham AB, Spitz DR, Zhao Z, Mathews TP, Morrison SJ (2020) Lymph protects metastasizing melanoma cells from ferroptosis. Nature 585: 113-118

Velichkova M, Hasson T (2005) Keap1 Regulates the Oxidation-Sensitive Shuttling of Nrf2 into and out of the Nucleus via a Crm1-Dependent Nuclear Export Mechanism. Molecular and Cellular Biology 25: 4501-4513

Wang L, Zhang C, Qin L, Xu J, Li X, Wang W, Kong L, Zhou T, Li X (2018) The prognostic value of NRF2 in solid tumor patients: a meta-analysis. Oncotarget 9: 1257-1265

Weiss RH, Estabrook RW (1986) The mechanism of cumene hydroperoxide-dependent lipid peroxidation: the significance of oxygen uptake. Arch Biochem Biophys 251: 336-47

Wong-Ekkabut J, Xu Z, Triampo W, Tang IM, Tieleman DP, Monticelli L (2007) Effect of lipid peroxidation on the properties of lipid bilayers: a molecular dynamics study. Biophysical journal 93: 4225-36

Wu KC, Cui JY, Klaassen CD (2011) Beneficial Role of Nrf2 in Regulating NADPH Generation and Consumption. Toxicological Sciences 123: 590-600

Yeow I, Howard G, Chadwick J, Mendoza-Topaz C, Hansen CG, Nichols BJ, Shvets E (2017) EHD Proteins Cooperate to Generate Caveolar Clusters and to Maintain Caveolae during Repeated Mechanical Stress. Current biology : CB 27: 2951-2962.e5

Zou Y, Graham ET, Huang Y, Salmon W, Yu L, Schreiber SL (2020) PALP: An imaging method for detecting and quantifying polyunsaturated phospholipids via peroxidation. bioRxiv: 2020.04.11.037218 
bioRxiv preprint doi: https://doi.org/10.1101/2021.06.09.447684; this version posted June 9, 2021. The copyright holder for this preprint (which was not certified by peer review) is the author/funder. All rights reserved. No reuse allowed without permission. 


\section{Figure Legends}

Figure 1 - Comparative proteomics and pathway analysis reveal significant change in oxidative stress pathway in CAVIN1-null cells.

A Heatmap representing the $\log _{2}$ Label Free Quantification (LFQ) intensities of MSidentified proteins in both WT and CAVIN1 KO cells (see values in Table EV1).

B Volcano plot showing altered proteins CAVIN1 KO cells relative to WT control. The curved line represents the significance threshold, determined by false discovery rate (FDR) based statistics $(\mathrm{FDR}<1 \%, \mathrm{~s} 0=1.5)$.

C Heat map displaying relative changes in differentially expressed proteins. Values have been z-scored.

D Top toxicity pathways upregulated in CAVIN1 KO cells.

E Top upstream regulators responsible for upregulated pathways in CAVIN1 KO cells, see entire list in Table EV2.

F Cluster analysis identified biological function of NRF2 downstream targets.

\section{Figure 2 - Loss of CAVIN1 leads to increased oxidative stress resistance.}

A DCF fluorescence normalized to total protein amount $(\mu \mathrm{g})$ in each group (one-way ANOVA). Western blot detected CAVIN1 levels in each sample with GAPDH as loading control.

B CellROX Green (5 $\mu \mathrm{M}, 30 \mathrm{~min})$ stained cells. Red circles outline the nucleus. Scale bar, 10 $\mu \mathrm{m}$.

C CellROX Green fluorescence (Student's $t$-test, $\mathrm{n}=50$ cells per experiment).

D A graphical depiction of the $\mathrm{H}_{2} \mathrm{O}_{2}$ scavenging assay.

E Representative images of colored reaction samples. $\mathrm{H}_{2} \mathrm{O}$ was added as a negative control.

F Absorbance values at $510 \mathrm{~nm}$ were compared using one-way ANOVA. 
G Cell growth curves of WT and CAVIN1 KO cells. Statistical difference at each time point was analyzed using two-way ANOVA.

H Relative DCF fluorescence (two-way ANOVA, ns=no significance).

I PrestoBlue assays were performed on cells after $48 \mathrm{~h}$ incubation with Vitamin $\mathrm{C}$ (two-way ANOVA). Colored curve represents different experiment.

J Relative DCF fluorescence in cells with $\mathrm{H}_{2} \mathrm{O}_{2}$ treatment.

K CellROX Green fluorescence in cells. Scale bar, $10 \mu \mathrm{m}$.

L CellROX Green intensities were compared using two-way ANOVA. Colored dots represent different experiments.

M Live confocal images displaying DCF fluorescence in skeletal muscle cells of $2 \mathrm{dpf}$ WT and cavinla/lb DKO zebrafish subjected to $2 \mathrm{mM} \mathrm{H}_{2} \mathrm{O}_{2}$ for $1 \mathrm{~h}$.

$\mathrm{N}$ Quantification and statistical analysis of DCF signal in $\mathrm{H}_{2} \mathrm{O}_{2}$-treated zebrafish normalized with DCF signal of clutch-matched untreated controls (Student's $t$-test, $\mathrm{n}=16$ WT zebrafish and $\mathrm{n}=17$ cavinla/lb DKO zebrafish, respectively, from 3 clutches per line). Colored dots represent different clutches.

$\mathrm{O}$ PrestoBlue assays assessed cell viability after exposure to $\mathrm{H}_{2} \mathrm{O}_{2}$ for $24 \mathrm{~h}$. Relative values compared to untreated control cells are represented as the survival curve (\%). Two-way ANOVA was used to compare the values at each time point.

P Western blot detected NRF2, $\gamma \mathrm{H} 2 \mathrm{AX}$ and cleaved CASP3 (caspase 3) protein levels. ACTB ( $\beta$-actin) was detected as loading control.

\section{Figure 3 - CAVIN1 mediate NRF2 ubiquitination and degradation.}

A Western blotting analysis of NRF2 protein expression following $0.2 \mathrm{mM} \mathrm{H}_{2} \mathrm{O}_{2}$ treatment over a 120 min time course.

B Relative NRF2 intensity values in (A) were calculated and statistically compared against NRF2 intensity at 0 min for both WT and CAVIN1 KO cells (two-way ANOVA).

C NRF2 immunofluorescence in untreated and $\mathrm{H}_{2} \mathrm{O}_{2}$-treated WT HeLa cells. Scale bar, 10 
$\mu \mathrm{m}$. D The ratio of nuclear to cytoplasmic NRF2 intensity (nuc vs. cyto) was calculated $(\mathrm{n}=50$ cells per experiment $)$ and compared using two-way ANOVA.

E, F NRF2 immunostaining in CAVIN1 KO cells transfected with GFP-vector (E) or CAVIN1-GFP (F) and treated with $\mathrm{H}_{2} \mathrm{O}_{2}(0.2 \mathrm{mM}, 60 \mathrm{~min})$. Scale bar, $10 \mu \mathrm{m}$.

$\mathrm{G}$, H Fold changes $\left(\mathrm{H}_{2} \mathrm{O}_{2}\right.$ treated:untreated) of NQO1 transcripts in CAVIN1 KO cells $(\mathrm{G})$ and in cavinlalb DKO zebrafish $(\mathrm{H})$ following 80 min $\mathrm{H}_{2} \mathrm{O}_{2}$ treatment (Student's $t$-test). TBP was used as a housekeeping gene.

I, J Confocal images showing PLA signal of NRF2-ubiquitin association in WT (I) and CAVIN1 KO (J) cells. MG132 $(10 \mu \mathrm{M})$ was applied to cells for $3 \mathrm{~h}$ prior to $\mathrm{H}_{2} \mathrm{O}_{2}$ treatment.

K Quantification and statistical analysis of PLA signal ( $\mathrm{n}=50$ cells per experiment, two-way ANOVA).

L Cells were treated with MG132 at $10 \mu \mathrm{M}$ for $3 \mathrm{~h}$ and were then subjected to $1 \mathrm{mM} \mathrm{H}_{2} \mathrm{O}_{2}$ treatment for $60 \mathrm{~min}$. Ubiquitin was then examined in NRF2 pull-down samples. Upregulated ubiquitination levels of NRF2 observed at 60 min post $\mathrm{H}_{2} \mathrm{O}_{2}$ treatment in WT cells might be related to the increased de novo synthesis of NRF2 (Fig. EV3D) and the quick recovery of KEAP1 after a transient inactivation for around 20 min following $\mathrm{H}_{2} \mathrm{O}_{2}$ treatment in $\mathrm{HeLa}$ cells as reported previously (Fourquet, Guerois et al., 2010).

M Western blotting analysis of NRF2 levels following CHX $(50 \mu \mathrm{g} / \mathrm{mL})$ treatment.

N Relative NRF2 levels in CHX chase assays was calculated.

\section{Figure 4 - Lipid peroxidation leads to CAVIN1 release and the interaction between} CAVIN1 and NRF2 in the cytosol.

A-C Confocal images showing CAVIN1 distribution in untreated (A) or $\mathrm{H}_{2} \mathrm{O}_{2}$ treated (B and C) WT HeLa cells. Scale bar, $10 \mu \mathrm{m}$.

D-I Live cell imaging of WT HeLa cells co-transfected with CAVIN1-GFP and CAV1mCherry with $1 \mathrm{mM} \mathrm{H}_{2} \mathrm{O}_{2}$ treatment. Insets shows enlargement of the selected areas. Scale bar, $10 \mu \mathrm{m}$.

J PLA signal showing the CAVIN1-NRF2 association before and after $60 \min \mathrm{H}_{2} \mathrm{O}_{2}$ 
treatment. PLA signal alone and DAPI staining in merged images were inverted to grey scale. Phalloidin staining (blue) labels the boundary of the cells. Scale bar, $10 \mu \mathrm{m}$.

K PLA signal per cell in (J) was statistically analyzed using one-way ANOVA.

L-N Immunoprecipitation assays assessed the interaction between NRF2 and CAVIN1 upon 60 min $\mathrm{H}_{2} \mathrm{O}_{2}$ treatment in both anti-NRF2 pull-down samples (L) and anti-CAVIN1 pulldown samples (M). Anti-IgG pull-down samples $(\mathrm{N})$ were assessed as negative controls.

O, P Quantification and statistical analysis of CAVIN1 levels (O) or NRF2 levels (P) in pulled down samples using one-way ANOVA. Colored dots represent different experiments.

Q Confocal images showing lipid peroxidation in WT cells using B-C11 probes. Scale bar, $10 \mu \mathrm{m}$.

R Fold changes of ox-B-C11:re-B-C11 were statistically analyzed by one-way ANOVA.

S Immunofluorescence assays showing the effect of $\alpha$-Tocopherol $(25 \mu \mathrm{M})$ on CAVIN1 (green) and NRF2 (red) distribution. Nuclei are indicated as red circles in the inverted grey scale images and as white circles in the merged images. Scale bar, $10 \mu \mathrm{m}$.

T PLA signal of CAVIN1-NRF2 association, scale bar, $10 \mu \mathrm{m}$.

U PLA signal in (T) was quantified and compared using two-way ANOVA.

\section{Figure 5 - Released CAVIN1 upon membrane lipid peroxidation regulates ferroptosis.}

A Confocal images showing endogenous CAVIN1 puncta at the PM in WT HeLa cells. In the selected region (green frame), cells were subjected to $405 \mathrm{~nm}$ laser pulses at the PM. Scale bar, $10 \mu \mathrm{m}$.

B Enlarged image showing CAVIN1 puncta at the PM in the laser-treated cell.

C, D Gray values of ox-B-C11 signal (C) and re-B-C11 (D) in the treated region were quantified to over $80 \mathrm{~s}$ following laser treatment.

E Immunofluorescence showing endogenous CAVIN1 puncta in cells pre-treated with $\alpha$ Tocopherol. Green frame indicates the region subjected to $405 \mathrm{~nm}$ laser pulses. Scale bar, 10 
$\mu \mathrm{m}$.

F Enlarged image showing CAVIN1 puncta at the PM in the laser-treated cell in the presence of $\alpha$-Tocopherol $(25 \mu \mathrm{M})$.

G, H Oxidized $(\mathrm{G})$ and reduced $(\mathrm{H})$ B-C11 signal were quantified for the treated region presented in $(\mathrm{E})$.

I The number of CAVIN1 puncta at the PM in untreated and laser treated cells with or without pre-treatment by $\alpha$-Tocopherol (two-way ANOVA).

J, K SYTOX Green staining revealed ferroptotic WT (J) or CAVIN1 KO \#2 (K) cells following 24-h RSL3 or Erastin2 treatment with or without pre-treatment by $\alpha$-Tocopherol $(25 \mu \mathrm{M})$. DAPI staining indicates the total number of cells in each frame. Scale bar, $10 \mu \mathrm{m}$.

L, M The percentage (\%) of SYTOX Green positive cells were calculated and statistically analyzed using one-way ANOVA.

N GPX4 levels were detected by western blot assays.

O Relative GPX4 levels were calculated, and significant change was indicated by two-way ANOVA.

\section{Figure 6 - A graphical summary illustrating the molecular role of CAVIN1 in response to oxidative stress.}

Oxidative stress-induced lipid peroxidation leads to CAVIN1 release from caveolae to the cytosol. This is essential for the sequestration and degradation of NRF2 and leads to cell deaths. In contrast, loss of CAVIN1 allows a more efficient NRF2 nuclear import upon oxidative stress and up-regulated activation of NRF2 downstream antioxidant enzymes. This confers enhanced antioxidant capacities to the cells and resistance to excess ROS-induced cell cytotoxicity. 


\section{Expanded View Figure Legends}

\section{Figure EV1 - Generation and characterization of CAVIN1 KO cell lines.}

A Transcript levels of CAV1, CAVIN1, CAVIN2 and CAVIN3 in HeLa cells assessed by realtime PCR.

B TALEN-targeting region is highlighted in red in human CAVINl human gene sequence.

C Western blot detection of CAVIN1 protein in different clones.

D Deletions (dashes) detected in a total of six bacterial clones by DNA sequencing. The region marked in red indicates the TALEN-targeting sites.

E Designed guide RNA sequence and target sites in human CAVIN1 gene.

F DNA sequencing revealing a deletion in CAVIN1 gene in selected clone.

G T7 endonuclease mismatch assays were performed to evaluate the gene editing efficiency of CRISPR/Cas9 in selected clones.

$\mathrm{H}$, I The mRNA levels of CAVINI (Taqman) $(\mathrm{H})$ and caveola associated components CAVIN3, CAV1, EHD2, PACSIN2 and ROR1 (SYBR Green) (I) were evaluated in WT, CAVIN1 KO (\#1) and CAVIN1-GFP expressing CAVIN1 KO (\#1) cells by real-time PCR assays. Statistical significance was determined by Student's $t$-test and two-way ANOVA for (H) and (I) respectively.

$\mathrm{J}$ The mRNA levels of CAVIN1 and caveola associated components were evaluated in WT, CAVIN1 KO (\#2) and CAVIN1-GFP expressing CAVIN1 KO (\#2) cells by real-time PCR assays (SYBR Green) and compared using two-way ANOVA.

$\mathrm{K}$, L The protein levels of CAVIN1 and caveola associated components were analyzed in WT, CAVIN1 KO and CAVIN1-GFP expressing CAVIN1 KO cells lines by western blotting, $\mathrm{n}=3$ independent experiments.

M, N Immunofluorescence showing the localization of CAVIN1, CAV1, CAVIN3 and EHD2 in HeLa WT and CAVIN1 KO cells. DAPI (blue) was stained to indicate the nucleus. Scale bar, $10 \mu \mathrm{m}$.

$\mathrm{O}, \mathrm{P}$ Immunofluorescence detected the localization of CAV1 (O) and CAVIN3 (P) in CAVIN1-GFP re-expressed CAVIN1 KO (\#1) cell line. Scale bar, $10 \mu \mathrm{m}$. 
Q-S Subcellular localization of CAV1, CAVIN3 and EHD2 in CAVIN1-GFP re-expressed CAVIN1 KO (\#2) cells was assessed by immunofluorescence. Scale bar, $10 \mu \mathrm{m}$.

T Quantification of the number of caveolae per cell from EM images.

\section{Figure EV2 - Generation and characterization of cavin1a/1b DKO zebrafish.}

A mRNA expression levels of cavinla and cavinlb in 5 dpf WT and cavin1a/1b DKO zebrafish (relative to b-actin). $\mathrm{N}=3$ clutches, performed in triplicate. Two-way ANOVA was used for statistical analysis.

B Survivability of cavinla/lb DKO zebrafish grown to $25 \mathrm{dpf}$ compared to WT ( $\mathrm{n}=71$ zebrafish [WT] and n=69 zebrafish [cavinla/lb DKO]; clutch number for both lines=3).

C Gross morphology of live WT and cavinla/lb DKO zebrafish at $3 \mathrm{dpf}$. Scale bar, $100 \mu \mathrm{m}$.

D Representative images of Nile Red staining of 26 dpf live WT and cavinla/lb DKO zebrafish visceral adipose. Scale bar, $100 \mu \mathrm{m}$.

E Body length (mm) of $3 \mathrm{dpf}$ WT and cavinla/lb DKO zebrafish (n=42 zebrafish [WT] and $\mathrm{n}=42$ zebrafish [cavin1a/lb DKO]; clutch number for both lines $=3$, colored dots represent different clutches).

F Representative live confocal images of BODIPY FL C5-ceramide labelled WT and cavinla/lb DKO zebrafish. Medial view of the zebrafish notochord and skeletal muscles. Arrowhead indicates a notochord lesion. Scale bar, $100 \mu \mathrm{m}$.

G TEM micrographs of skeletal muscle capillary and skeletal muscle of adult male WT and cavinla/lb DKO zebrafish (approximately 3 months post fertilization). Arrowhead indicates caveola. Capillary scale bar, $500 \mathrm{~nm}$; Skeletal muscle scale bar, $1 \mu \mathrm{m}$.

Figure EV3 - Lipid peroxidation is responsible for CAVIN1 release and allows for its interaction with NRF2 upon oxidative stress.

A DCF fluorescence in A431 cells with or without the depletion of CAVIN1. Three sets of siRNAs were used for comparison.

B Effect of re-expression of CAV1 on ROS levels in CAVIN1 KO cells was indicated by DCF fluorescence intensities.

C NRF2 localization in CAVIN1-deficient MCF-7 cells with or without re-expression of CAVIN1-GFP. Scale bar, $10 \mu \mathrm{m}$. 
D WT HeLa cells were left untreated (Unt) or incubated with $0.2 \mathrm{mM} \mathrm{H}_{2} \mathrm{O}_{2}$ for $60 \mathrm{~min}$. NRF2 transcript expression levels were measured and normalized to TBP that was used as the control. Statistical analysis was performed $(\mathrm{N}=3$ experiments, Student's $t$-test).

E Representative confocal images of immunofluorescence showing CAVIN1 distribution before and after treatment of $\mathrm{H}_{2} \mathrm{O}_{2}$. Scale bar, $10 \mu \mathrm{m}$.

F, G EM images displaying caveolar levels in untreated and $\mathrm{H}_{2} \mathrm{O}_{2}$ treated $\mathrm{A} 431$ cells. Caveolae are highlighted in red.

H Quantification of caveola number in A431 cells from EM images was analyzed using Student's $t$-test.

I PLA images showing association of NRF2 and CAVIN1 in cells with or without $\mathrm{H}_{2} \mathrm{O}_{2}$ treatment. Yellow circles indicate cellular boundaries. Scale bar, $10 \mu \mathrm{m}$.

J Effects of $\alpha$-Tocopherol at different concentrations on the inhibition of ROS levels in HeLa cells. Vitamin C treatment was included as a positive control.

K B-C11 signal was observed using confocal microscopy in A431 cells with different treatments. Scale bar, $10 \mu \mathrm{m}$.

L Ratio values (ox-B-C11:re-B-C11) for each group in (K) were statistically analyzed by using two-way ANOVA.

M Confocal images showing reduced and oxidized signals of B-C11 probes in HeLa cells with different treatments. Cumene hydroperoxide $(50 \mu \mathrm{M})$ was used for lipid peroxidation induction. Scale bar, $10 \mu \mathrm{m}$.

$\mathrm{N}$ The (ox-B-C11:re-B-C11) ratio for each group in (M) was compared using one-way ANOVA.

O Immunofluorescence showing CAVIN1 distribution following cumene hydroperoxide treatment in HeLa WT cells with or without pretreatment by $\alpha$-Tocopherol. Scale bar, $10 \mu \mathrm{m}$.

\section{Figure EV4 - Lipid peroxidation leads to CAVIN1 dissociation from caveolae.}

A, B Gray values of ox-B-C11 over 2 min in laser-treated HeLa cell (A, see full movie in Video EV1) and in untreated HeLa cell (B, see full movie in Video EV2).

C, D Images obtained at $0 \mathrm{~s}$ (C) and $120 \mathrm{~s}$ (D) following laser treatment showing the abundance of CAVIN1-GFP puncta at the PM, see full movie in Video EV3. 
E The changes in the number of CAVIN-GFP puncta in laser-treated cells over $120 \mathrm{~s}$ following laser treatment.

F, G Live cell imaging showing CAVIN1-GFP distribution at the PM in untreated cell over 120 s, see full movie in Video EV4.

$\mathrm{H}$ The number of CAVIN1-GFP puncta at the PM in untreated HeLa cell over 120 seconds.

I-L Endogenous CAVIN1 was stained in untreated or UV-irradiated HeLa cells with or without pretreatment by $\alpha$-Tocopherol. Scale bar, $10 \mu \mathrm{m}$.

M Quantification of the number of CAVIN1 puncta per $\mu \mathrm{m}^{2}$ at the PM showing in (I-L). Two-way ANOVA analysis was used for comparing the statistical difference. 
Table 1. NRF2 downstream targets in CAVIN1 KO HeLa cells identified by IPA.

\begin{tabular}{|c|c|c|c|c|}
\hline $\begin{array}{l}\text { Gene Symbol } \\
\text { for human } \\
\text { (HUGO/HGNC } \\
\text { /Entrez Gene) }\end{array}$ & Entrez Gene Name & $\begin{array}{l}\text { Fold } \\
\text { change }\end{array}$ & Localization & Family \\
\hline ALDOA & aldolase, fructose-bisphosphate A & 1.94 & Cytoplasm & enzyme \\
\hline ATF7 & activating transcription factor 7 & 1.90 & Nucleus & $\begin{array}{l}\text { transcription } \\
\text { regulator }\end{array}$ \\
\hline CBR1 & carbonyl reductase 1 & 1.55 & Cytoplasm & enzyme \\
\hline СCT3 & chaperonin containing TCP1 subunit 3 & 2.30 & Cytoplasm & other \\
\hline CCT7 & chaperonin containing TCP1 subunit 7 & 1.68 & Cytoplasm & other \\
\hline CHORDC1 & $\begin{array}{l}\text { cysteine and histidine rich domain } \\
\text { containing } 1\end{array}$ & 3.28 & Other & other \\
\hline EIF2S1 & $\begin{array}{l}\text { eukaryotic translation initiation factor } 2 \\
\text { subunit alpha }\end{array}$ & 1.46 & Cytoplasm & $\begin{array}{l}\text { translation } \\
\text { regulator }\end{array}$ \\
\hline EIF3E & $\begin{array}{l}\text { eukaryotic translation initiation factor } 3 \\
\text { subunit E }\end{array}$ & 1.74 & Cytoplasm & other \\
\hline EIF3G & $\begin{array}{l}\text { eukaryotic translation initiation factor } 3 \\
\text { subunit G }\end{array}$ & 2.03 & Cytoplasm & other \\
\hline EIF4G2 & $\begin{array}{l}\text { eukaryotic translation initiation factor } 4 \\
\text { gamma } 2\end{array}$ & 1.54 & Cytoplasm & $\begin{array}{l}\text { translation } \\
\text { regulator }\end{array}$ \\
\hline & & & Plasma & \\
\hline EPHB4 & EPH receptor B4 & 1.60 & Membrane & kinase \\
\hline GSTO1 & glutathione S-transferase omega 1 & 2.52 & Cytoplasm & enzyme \\
\hline HPRT1 & $\begin{array}{l}\text { hypoxanthine phosphoribosyltransferase } \\
1\end{array}$ & 3.46 & Cytoplasm & enzyme \\
\hline HSP90AA1 & $\begin{array}{l}\text { heat shock protein } 90 \text { alpha family class } \\
\text { A member } 1\end{array}$ & 1.60 & Cytoplasm & enzyme \\
\hline & inosine monophosphate dehydrogenase & & & \\
\hline IMPDH1 & 1 & 2.37 & Cytoplasm & enzyme \\
\hline LMNA & $\operatorname{lamin} \mathrm{A} / \mathrm{C}$ & 1.46 & Nucleus & other \\
\hline MGST3 & microsomal glutathione S-transferase 3 & 1.27 & Cytoplasm & enzyme \\
\hline MORF4L2 & mortality factor 4 like 2 & 1.42 & Nucleus & other \\
\hline \multirow[t]{2}{*}{ NARS } & asparaginyl-tRNA synthetase & 2.12 & Cytoplasm & enzyme \\
\hline & platelet activating factor acetylhydrolase & & & \\
\hline PAFAH1B1 & $1 \mathrm{~b}$ regulatory subunit 1 & 2.05 & Cytoplasm & enzyme \\
\hline PGD & phosphogluconate dehydrogenase & 1.65 & Cytoplasm & enzyme \\
\hline PHGDH & phosphoglycerate dehydrogenase & 2.04 & Cytoplasm & enzyme \\
\hline PRDX1 & peroxiredoxin 1 & 2.24 & Cytoplasm & enzyme \\
\hline PSAT1 & phosphoserine aminotransferase 1 & 4.80 & Cytoplasm & enzyme \\
\hline
\end{tabular}




\begin{tabular}{lllll} 
PSMA4 & proteasome subunit alpha 4 & 2.00 & Cytoplasm & peptidase \\
PSMA6 & proteasome subunit alpha 6 & 2.00 & Cytoplasm & peptidase \\
PSMA7 & proteasome subunit alpha 7 & 1.64 & Cytoplasm & peptidase \\
PSMB1 & proteasome subunit beta 1 & 2.06 & Cytoplasm & peptidase \\
PSMB5 & proteasome subunit beta 5 & 2.87 & Cytoplasm & peptidase \\
& proteasome 26S subunit, non-ATPase & & & \\
PSMD11 & 11 & 1.26 & Cytoplasm & other \\
PSMD5 & proteasome 26S subunit, non-ATPase 5 & 2.76 & Other & other \\
GNB2L1 & receptor for activated C kinase 1 & 1.99 & Cytoplasm & enzyme \\
RARS & arginyl-tRNA synthetase & 1.91 & Cytoplasm & enzyme \\
S100A13 & S100 calcium binding protein A13 & 1.67 & Cytoplasm & other \\
& Sec23 homolog A, coat complex II & & & \\
SEC23A & component & 2.73 & Cytoplasm & transporter \\
STIP1 & stress induced phosphoprotein 1 & 2.42 & Cytoplasm & other \\
TALDO1 & transaldolase 1 & 2.18 & Cytoplasm & enzyme \\
TKT & transketolase & 3.28 & Cytoplasm & enzyme \\
TPI1 & triosephosphate isomerase 1 & 2.14 & Cytoplasm & enzyme \\
TXN & thioredoxin & 1.40 & Cytoplasm & enzyme \\
TXNRD1 & thioredoxin reductase 1 & 2.54 & Cytoplasm & enzyme \\
\hline & & & & \\
\hline
\end{tabular}


bioRxiv preprint doi: https://doi.org/10.1101/2021.06.09.447684; this version posted June 9, 2021. The copyright holder for this preprint

A
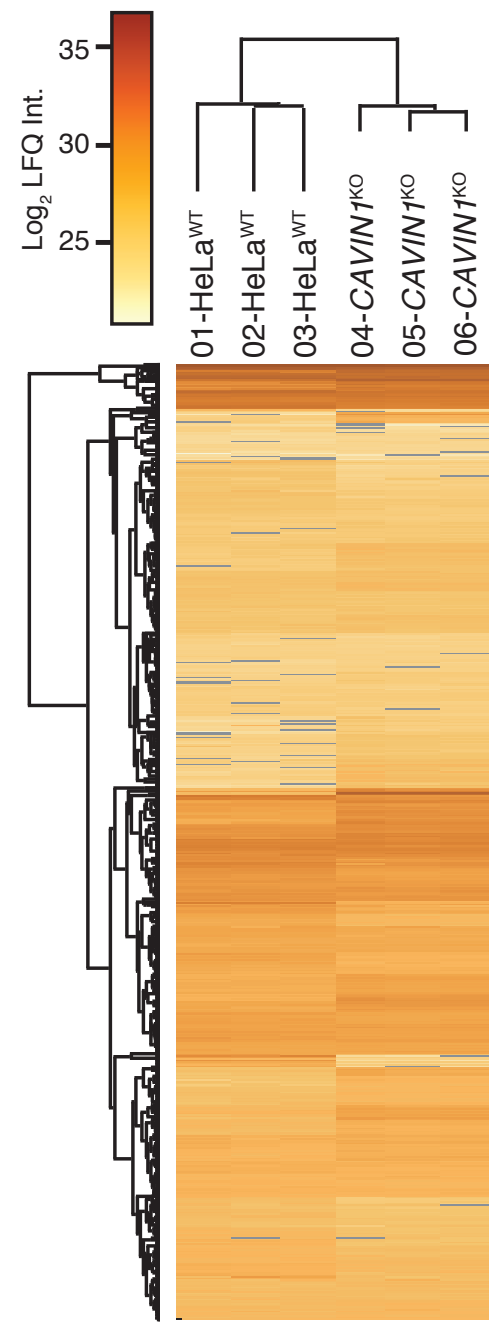

B

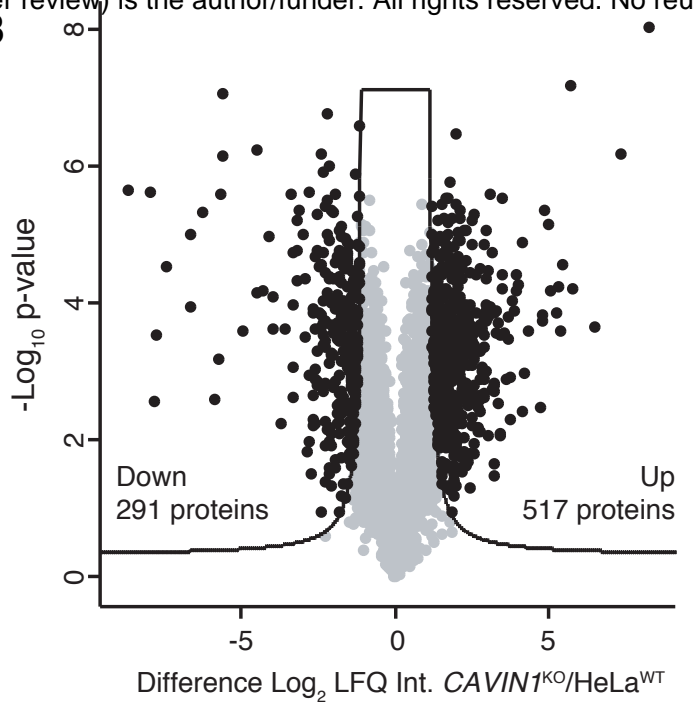

\section{Top Toxicity Pathways}

Pathway

NRF2-mediated oxidative stress response

Renal necrosis/Cell death

\section{E Top Upstream Regulators}

Name

MYC

1,2-dithiol-3-thione

5-fluoruracil

TP53

NFE2L2
C

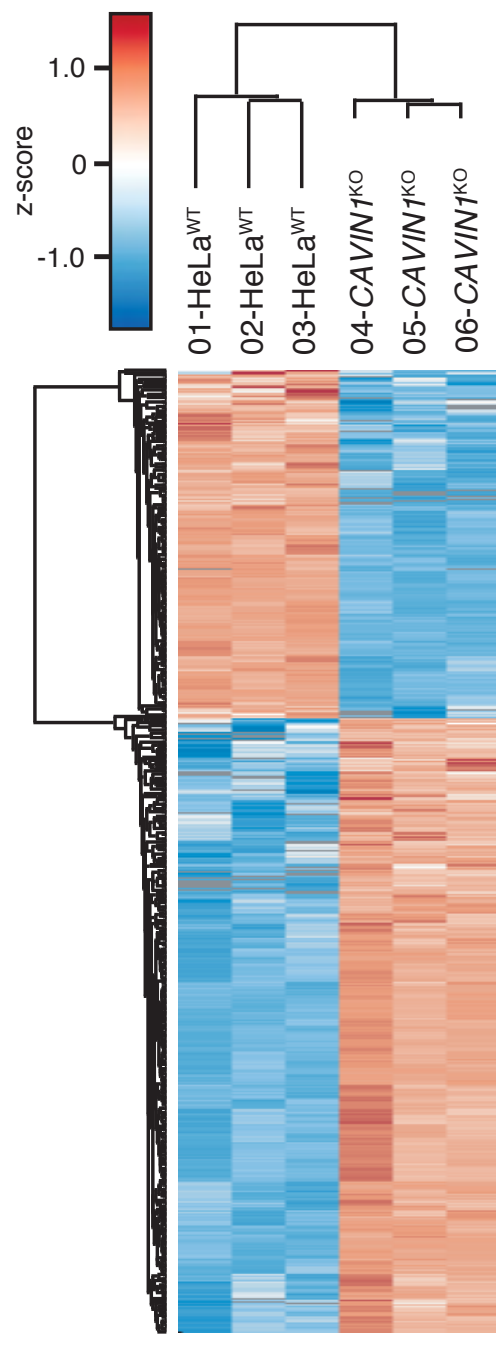

$\mathbf{F}$

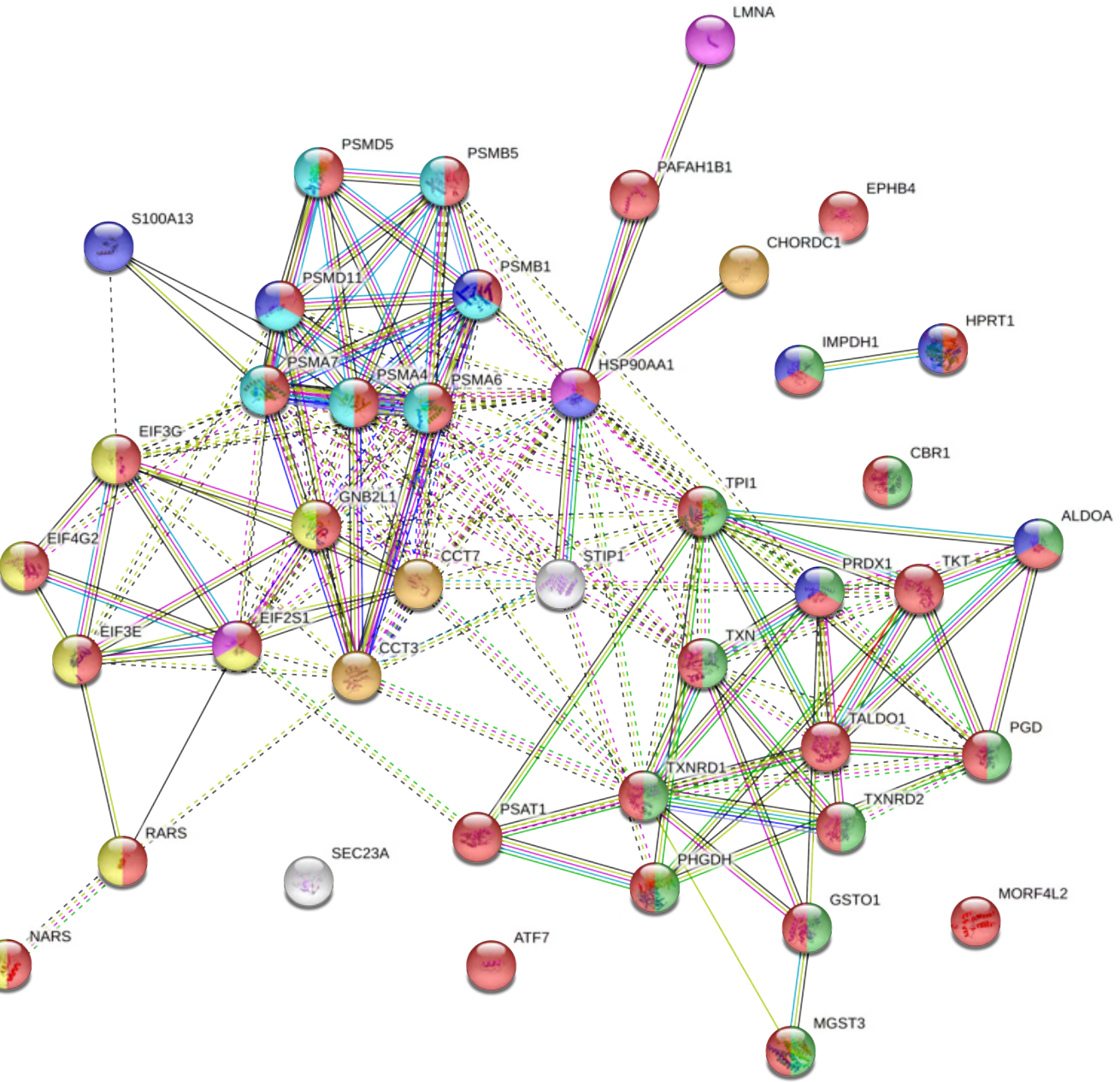

\section{Node color}

Enriched biological processes

Cellular metabolic process

Oxidation-reduction process

Protein deubiquitination

Translation

Leukocyte mediated immunity

Chaperone mediated protein folding

Response to unfolded protein

N/A

Edges
Known interactions
$-\quad$ from curated databases
$-\quad$ experimentally determined
Predicted interactions
- gene neighborhood
$-\quad$ gene fusions
Others gene co-occurrence
- textmining
- co-expression
- protein homology


bioRxiv preprint doi: https://doi.org/10.1101/2021.06.09.447684; this version posted June 9, 2021. The copyright holder for this preprint
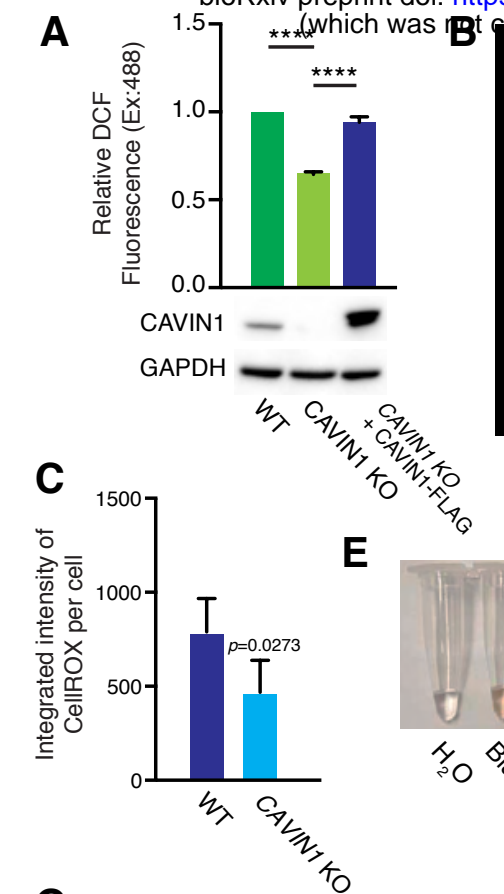

G

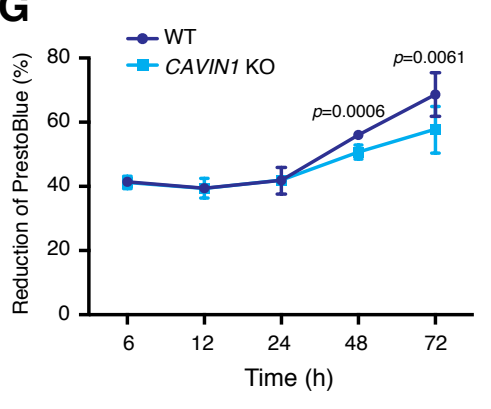

H
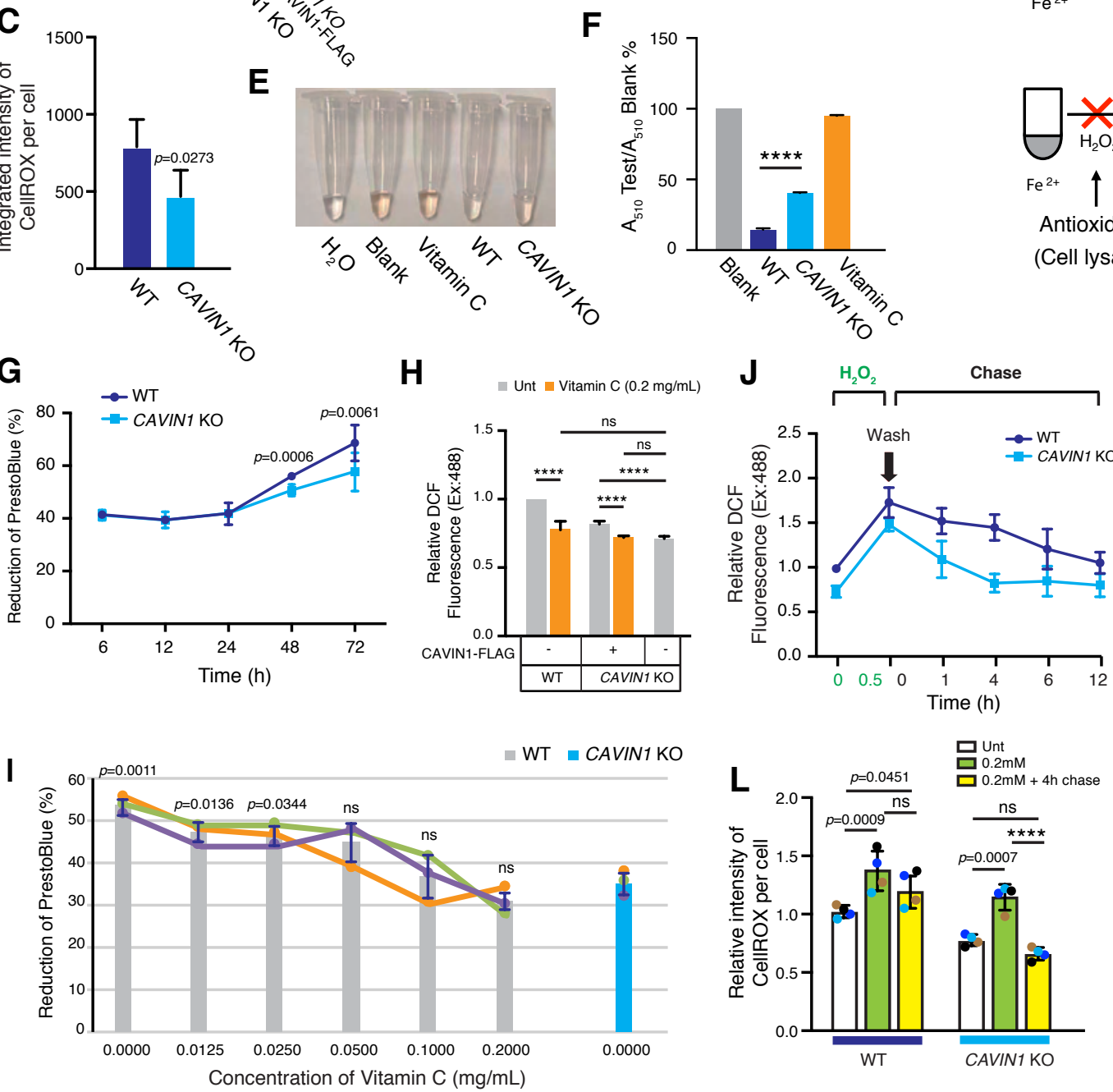

M

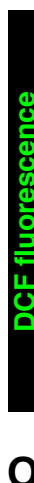

0

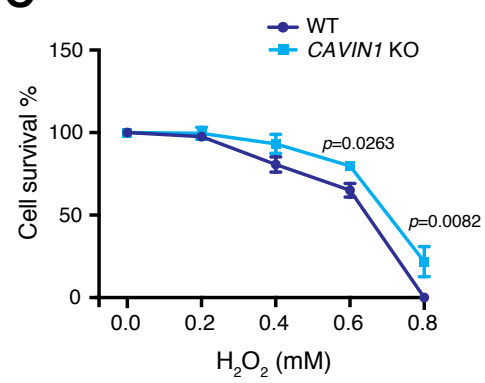

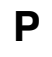

$\mathbf{P}$

CAVIN1 KO

\begin{aligned} & $\mathrm{H}_{2} \mathrm{O}_{2} \multicolumn{2}{c}{$ WT } \#2 \\ &$(1 \mathrm{mM}, 24 \mathrm{~h})-\end{aligned}$

NRF2 $t \rightarrow n+9+9$

$\gamma \mathrm{H} 2 \mathrm{AX}$

Cleaved $\quad 2=0$

ACTB $-\cdots$
CASP3 30 inc $\quad-17 \mathrm{kDa}$

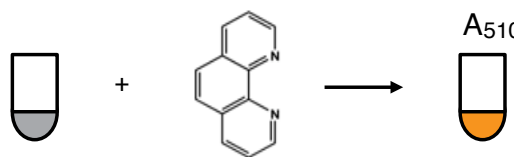

Ferrous $\left(\mathrm{Fe}^{2+}\right)$

1,10-phenanthroline $\quad \mathrm{Fe}^{2+}$-tri-phenanthroline Ammonium sulphate complex
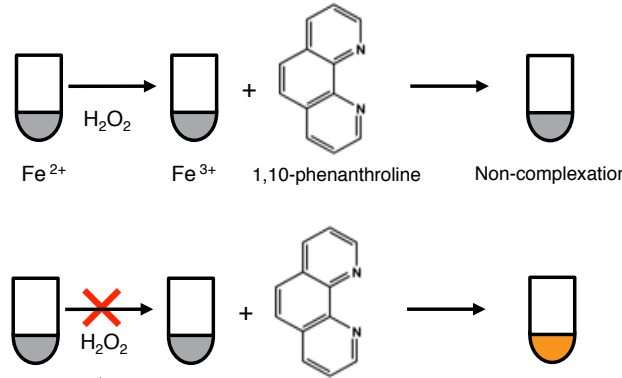

$\mathrm{Fe}^{2+} \uparrow \mathrm{Fe}^{2+}$ 1,10-phenanthroline $\mathrm{Fe}^{2+}$-tri-phenanthroline

Antioxidant

(Cell lysates)

$\mathbf{K}_{\mathrm{WT}}$

CAVIN1 KO

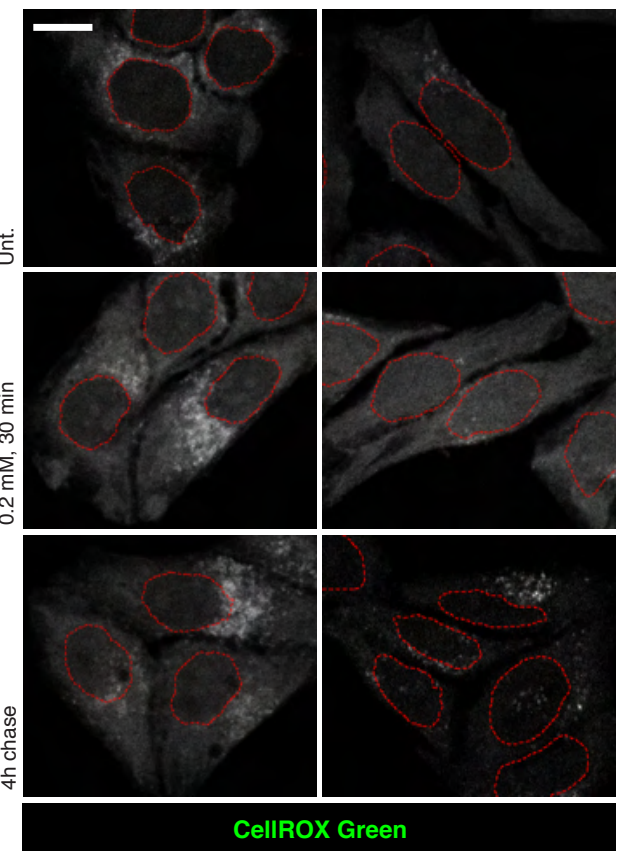

N

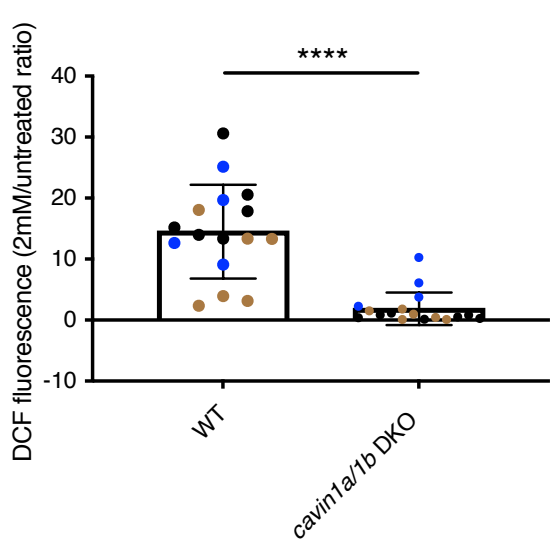


A bioRxiv preprint doi: https://doi.org/10.1101/2021.06.09.447684; this version posted June 9, 2021. The copyright holder for this preprint A
A
CAVIN1 KO \#2
CWT

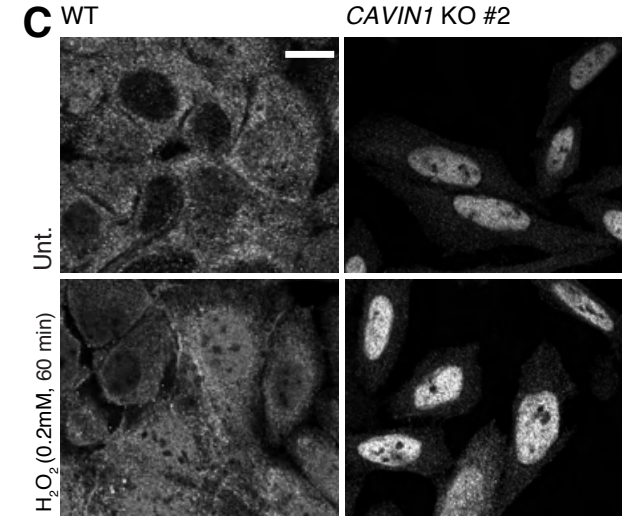

\section{G}

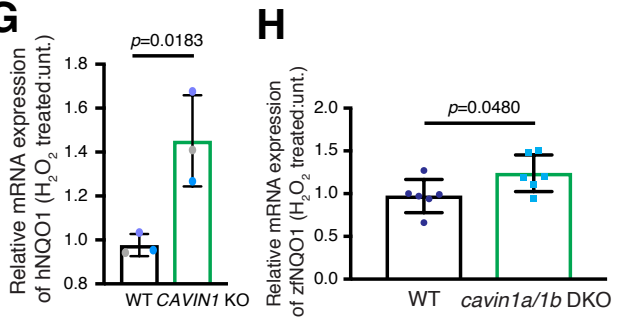

E

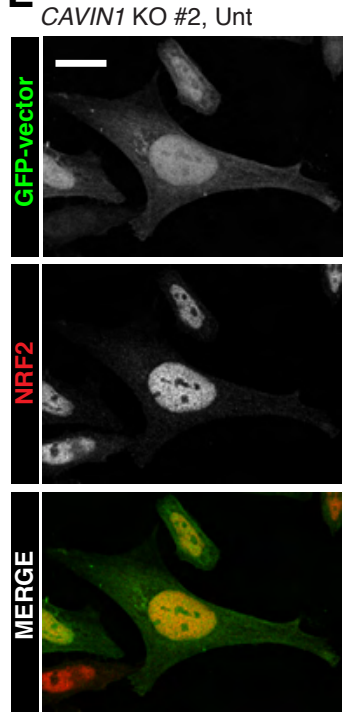

CAVIN1 $\mathrm{KO} \# 2, \mathrm{H}_{2} \mathrm{O}_{2}$

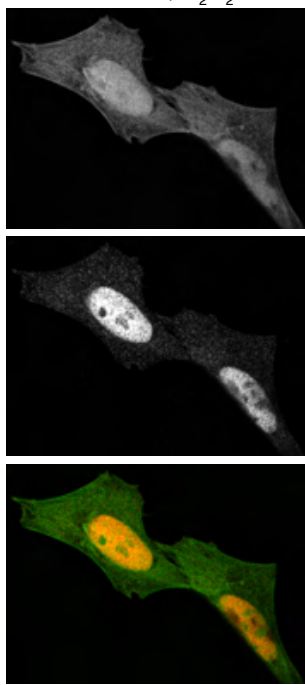

F

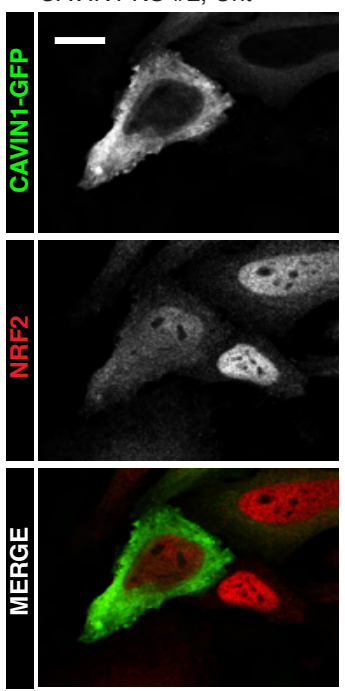

CAVIN1 KO \#2, $\mathrm{H}_{2} \mathrm{O}_{2}$

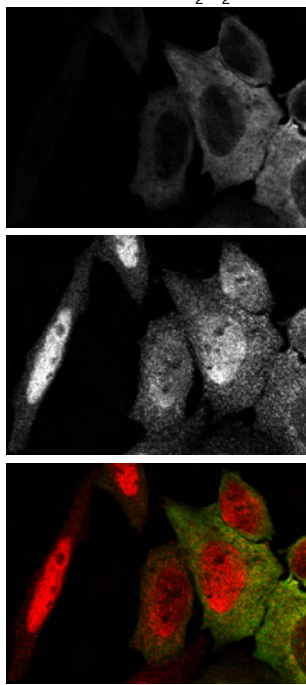

I

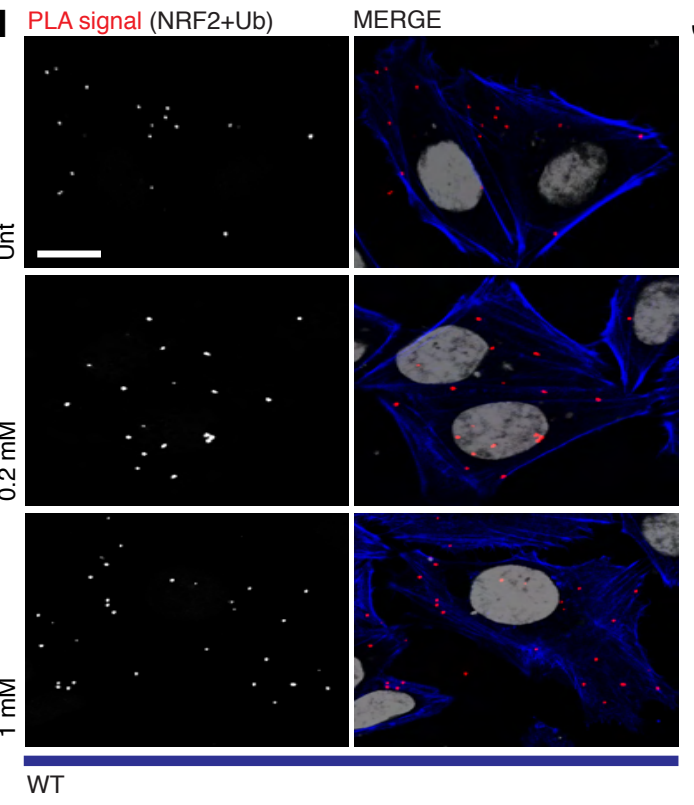

L $\mathrm{H}_{2} \mathrm{O}_{2}(1 \mathrm{mM})-++\frac{\text { WT CAVIN1 KO }}{-+}+$ WT CAVIN1 KO $^{-}$

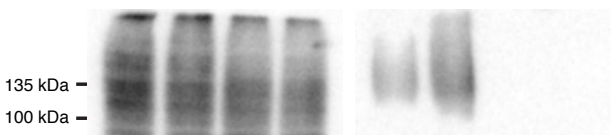

$75 \mathrm{kDa}-$

IB: Ub

anti-NRF2

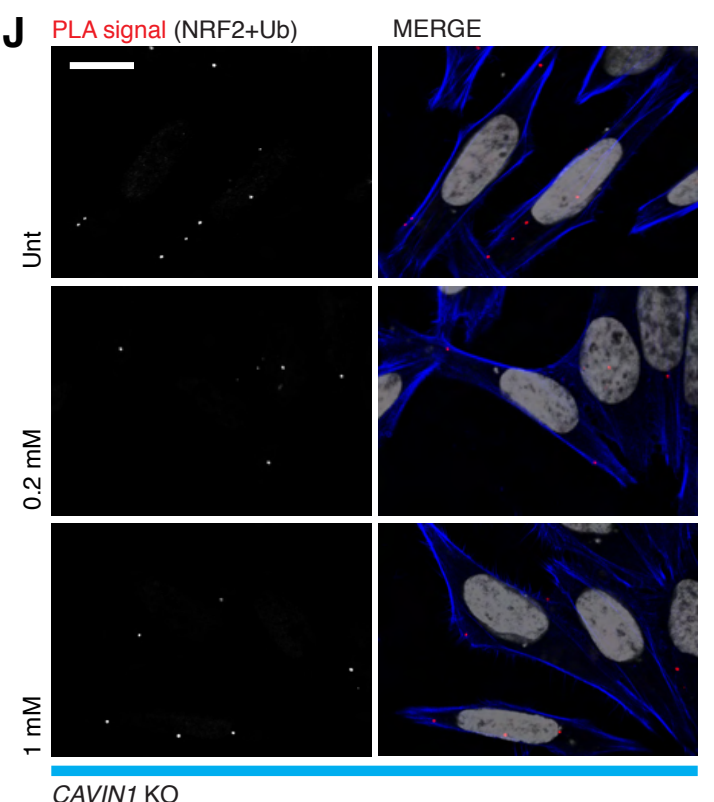

K

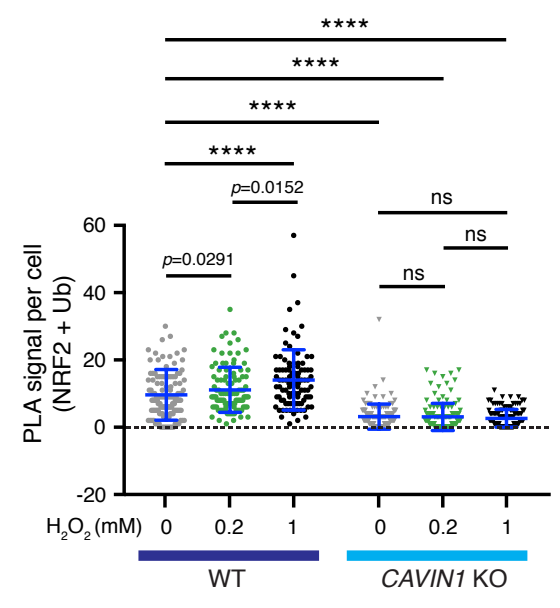

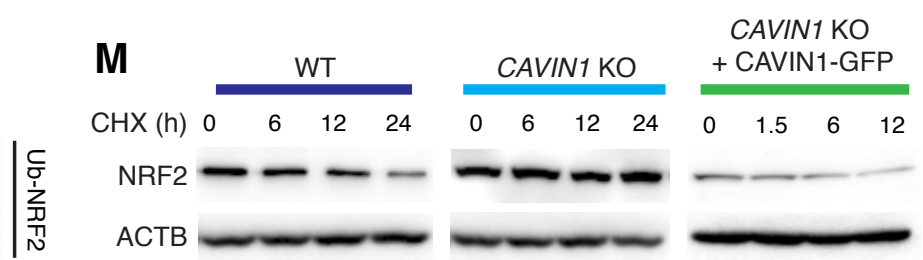

\section{N}

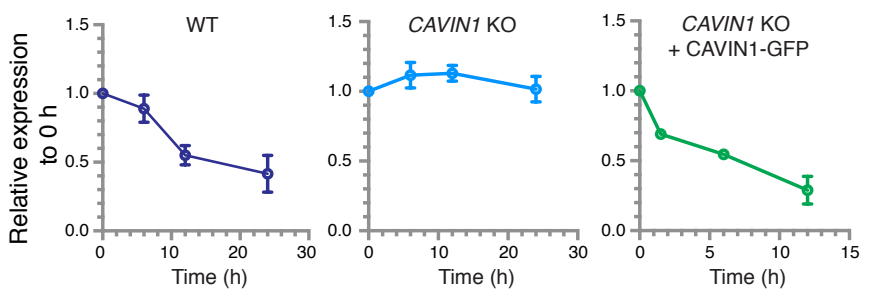




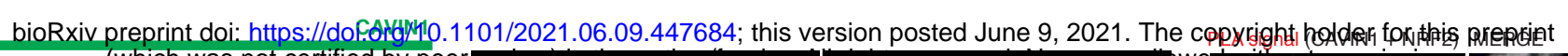

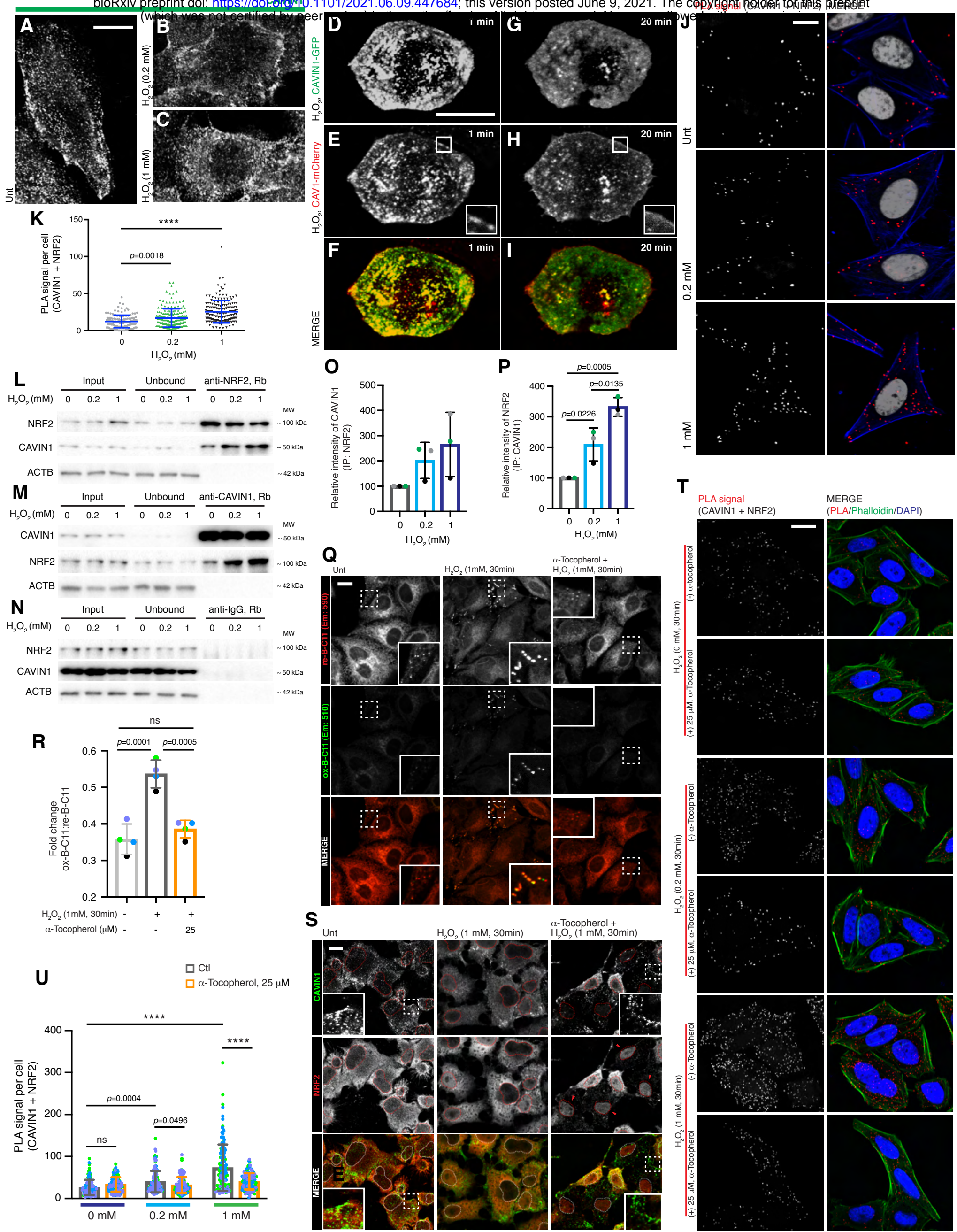


bioRxiv preprint doi: https://doi.org/10.1101/2021.06.09.447684; this version posted June 9, 2021. The copyright holder for this preprint (which was not certified by peer review) is the author/funder. All rights reserved. No reuse allowed without permission.

\section{Oxidative environment}

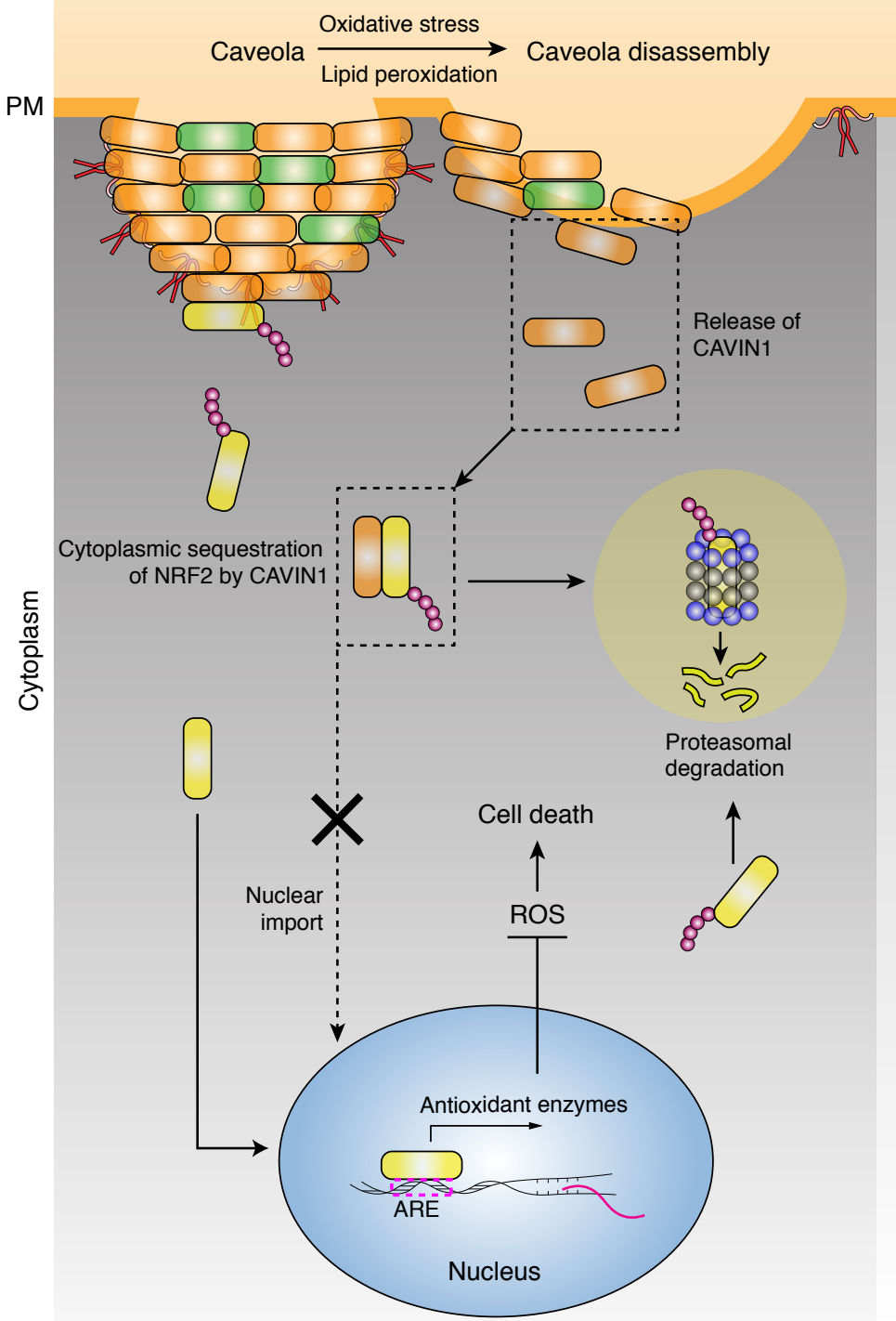

WILD-TYPE

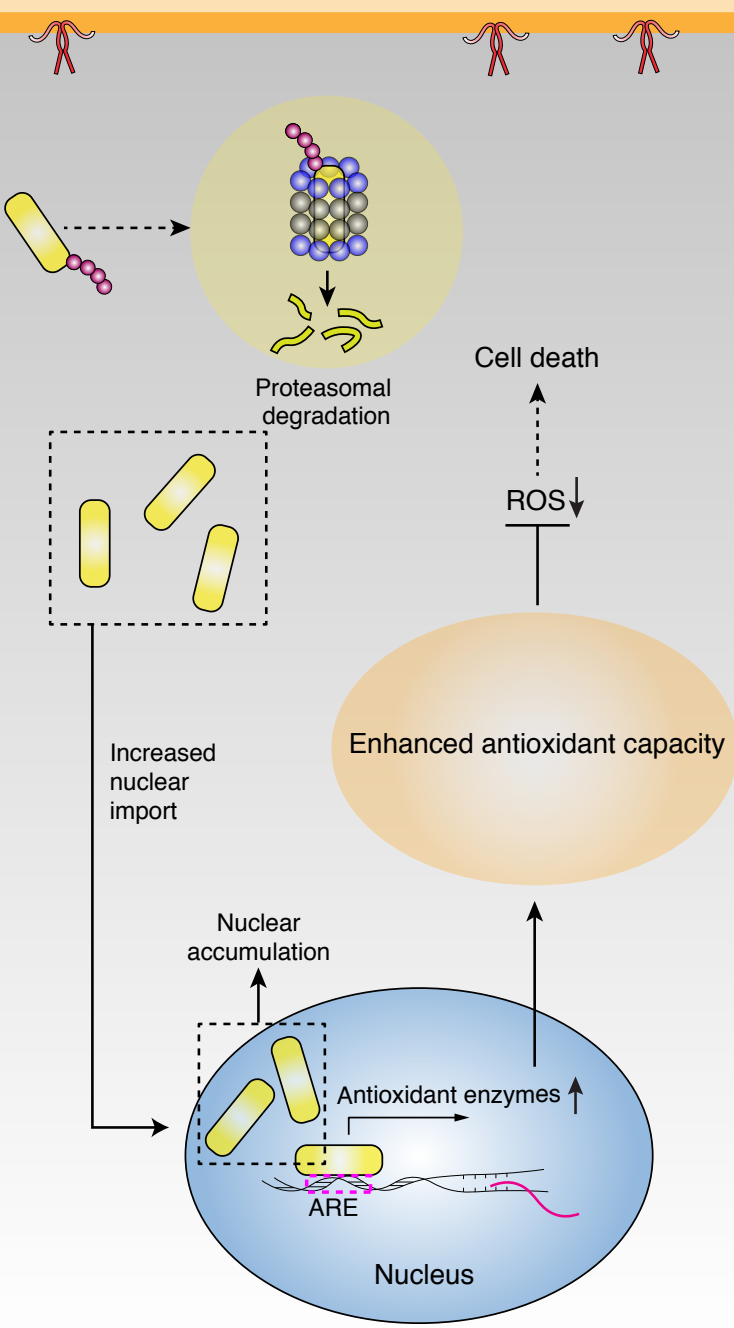

CAVIN1 KO

\begin{tabular}{|c|c|}
\hline$\hookrightarrow$ & CAVIN1 \\
\hline$\lessdot$ & NRF2 \\
\hline$\hookrightarrow$ & CAVIN3 \\
\hline $8^{\circ}$ & ubiquitin \\
\hline $\begin{array}{l}898 \\
8888\end{array}$ & $20 S$ proteasome \\
\hline
\end{tabular}

